\title{
A New Simulation Model for a Comprehensive Evaluation of Yard Truck Deployment Strategies at Marine Container Terminals
}

\author{
Maxim A. Dulebenets* \\ Florida A\&M University - Florida State University, Tallahassee, FL, \\ United States \\ *Corresponding Author: Maxim A. Dulebenets: mdulebenets@fsu.edu
}

\section{OPEN ACCESS}

Citation: Dulebenets MA. (2016) A New Simulation Model for a Comprehensive Evaluation of Yard Truck Deployment Strategies at Marine Container Terminals. Open Science Journal 1(3)

Received: $4^{\text {th }}$ September 2016

Accepted: $10^{\text {th }}$ October 2016

Published: $24^{\text {th }}$ October 2016

Copyright: (C) 2016 This is an open access article under the terms of the Creative Commons

Attribution License, which permits unrestricted use, distribution, and reproduction in any medium, provided the original author and source are credited.

Funding: The author(s) received no specific funding for this work.

Competing Interests: The author have declared that no competing interests exists.

\section{Abstract}

Taking into account increasing volumes of the international seaborne trade and increasing port congestion, marine container terminal operators have to improve efficiency of their operations in order to provide timely service of vessels and avoid product delivery delays to customers. This paper focuses on improvement of container transfer operations between the seaside and the marshaling yard and proposes five yard truck deployment strategies. Performance of the considered marine container terminal is evaluated under each one of the yard truck deployment strategies via simulation. Different performance indicators are estimated to determine how the suggested yard truck deployment strategies will affect all equipment types, involved in container handling and transfer. Results from the extensive simulation experiments showcase that all five yard truck deployment strategies provide similar values of vessel service and quay crane performance indicators, while the shortest distance based yard truck deployment strategy yields superior gantry crane and yard truck performance indicators. The worst values of performance indicators are recorded for the random yard truck deployment strategy. Furthermore, the developed simulation model can serve as an efficient planning tool for marine container terminal operators and enhance productivity of the available equipment. 
Keywords: Marine Container Terminals, Yard Trucks, Yard Truck Deployment Strategies, Simulation, Terminal Productivity

\section{Introduction}

Increasing port congestion significantly affects operations of liner shipping companies and marine container terminals (MCTs). Vessel arrival delays of 70 hours were reported in July 2014 at major European ports: Rotterdam, Hamburg, and Antwerp [1]. Container volumes decreased by $22.7 \%$ in January 2015 and by $10.2 \%$ in February 2015 at the Port of Los Angeles due to long congestion periods and labor issues [2]. The United Stated (U.S.) West Coast laden traffic declined by $12 \%$ in the first three months of 2015 . Some of vessels were diverted from the U.S. West Coast to the East and Gulf Coast ports [2]. American Shipper [3] underlines that port congestion is not a temporary phenomenon in the U.S. Port congestion existed even before labor strikes due inefficiency of MCT operations. The major factors, causing port congestion at the U.S. ports (some of which will be applicable to other world ports), include the following [3][4]: a) increasing size of vessels; b) liner shipping alliances; c) lack on innovative technologies for efficient port operations; and d) availability of chassis.

According to the Journal of Commerce [1], around 50\% of Post-Panamax vessels faced more than 12 hour delays at the North and South American ports in July 2014. Liner shipping companies continue increasing size of their vessels, while many MCT operators are still not able to upgrade the port infrastructure for service of megaships [5]. Formation of alliances provides more flexibility to liner shipping companies, as they are able to more efficiently share the demand. However, fluctuation in demand will require $\mathrm{MCT}$ operators to revise their original vessel service plans and in some cases will negatively affect the MCT productivity. Lack of innovation has been an issue at MCTs especially for the gate operations. At some MCTs drayage trucks (DTs) may arrive unannounced, which will further result in long queues at the gate [4]. Furthermore, sometimes due to lack of communication the DT driver does not even know the container status. Chassis shortage is another problem, causing congestion at the gate. DT drivers may be required to wait for a significant amount of time in order to find the chassis, on which the container will be placed. To alleviate port congestion and provide timely service of arriving vessels MCT operators have to improve efficiency of their operations [3][4].

MCT operations include seaside, marshalling yard, and landside operations. Seaside operations deal with berthing of vessels, stowage planning, quay crane (QC) assignment, and QC scheduling for (un)loading containers. Marshalling yard operations include stacking and retrieval of import, export, and transshipment containers by gantry cranes (GCs) at yard blocks. Internal transport vehicles (ITVs) provide container transfer between the seaside and the marshalling yard. Landside operations include receiving and/or delivering containers by DTs. There are three main transfer processes at MCTs: a) vesselto-yard (i.e., import), b) yard-to-vessel (i.e., export), c) and vessel-to-vessel (i.e., transshipment). Import and export operations are presented in Figure 1, while 
transshipment operations are shown in Figure 2. MCT operations can be described as follows: once a vessel enters the port, it is towed to the assigned berth by push boats. Then the vessel is moored, and ship-to-shore QCs start (un)loading containers. ITVs transfer containers between the seaside and preassigned blocks of the marshalling yard, where GCs arrange them either parallel or perpendicular to the berth. Import containers are delivered to the MCT by vessels, while export containers are moved to the MCT by DTs through the gates or by rail (if on-dock rail access exists). Once a DT enters a terminal, it either travels to the assigned yard block of the marshalling yard or to a dedicated receiving area, where the container is (un)loaded. Transshipment occurs, when cargo, delivered by one vessel (usually called as mother vessel), is moved to another vessel (usually called as feeder vessel). Transshipment containers can be transported from a vessel to another vessel with or without temporary storage in the marshalling yard.

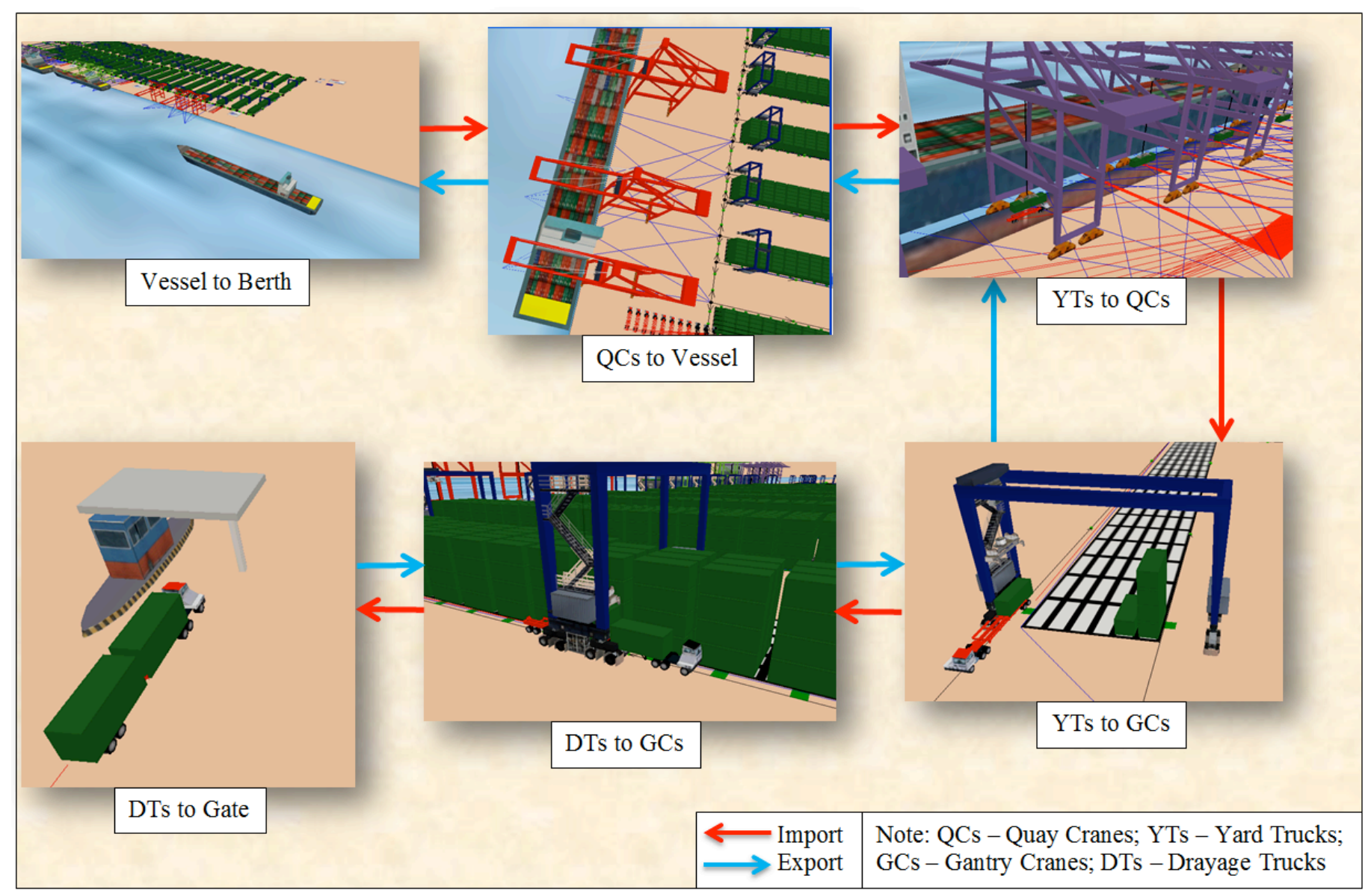

Figure 1: Import/export operations. 


\section{Open Science Journal}

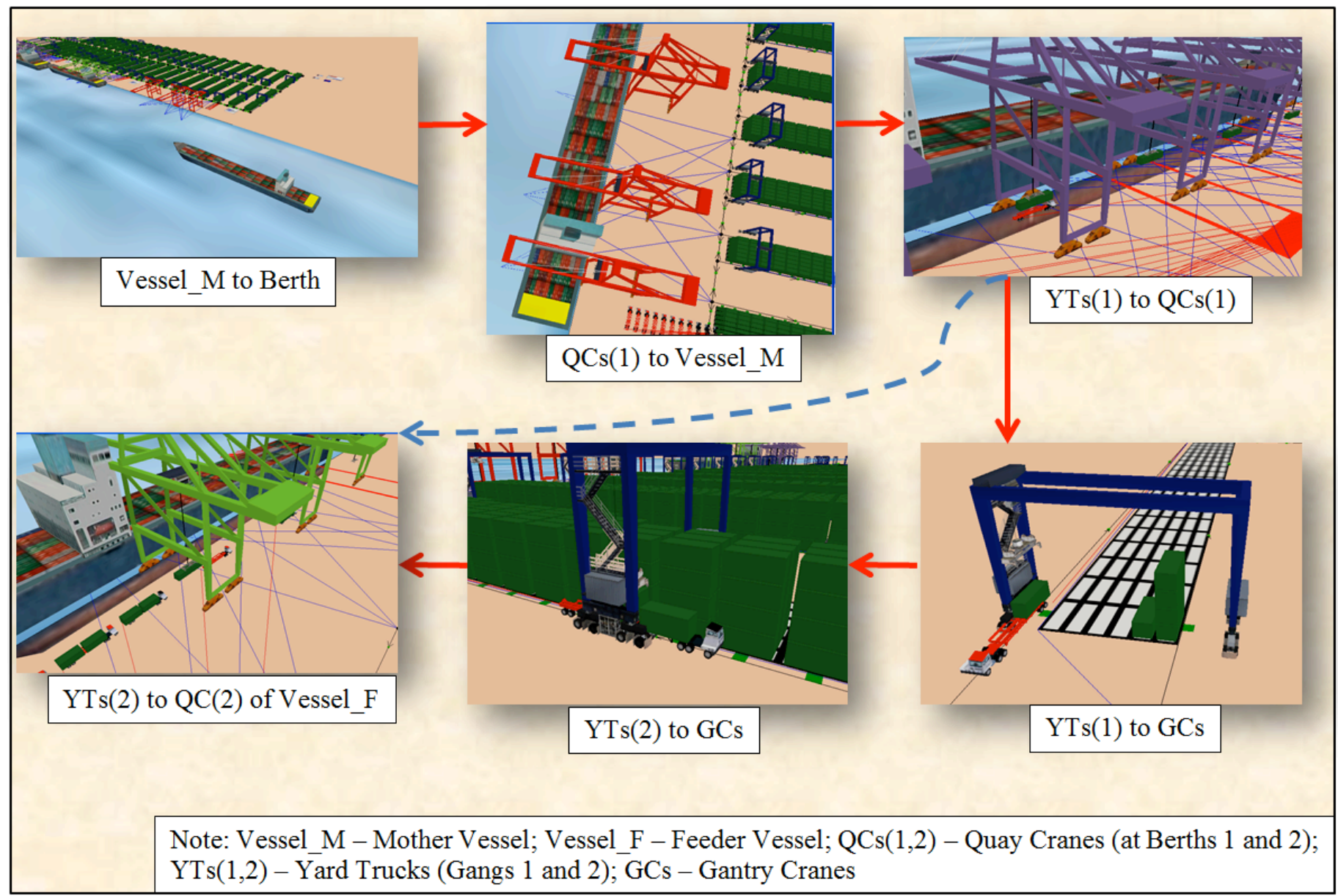

Figure 2: Transshipment operations.

This paper focuses on improving container transfer between the seaside and the marshaling yard at MCT, where yard trucks (YTs) are deployed as ITVs. A total of five YT deployment strategies are proposed and evaluated using simulation. The YT deployment strategies are compared based on various MCT performance indicators. Unlike many studies on the YT deployment, conducted in the past, this paper does not solely focus on performance indicators of a specific equipment type (e.g., only QCs or only YTs), but performs a comprehensive evaluation of all equipment types, involved in container handling and transfer between the seaside and the marshaling yard of MCT (i.e., QCs, YTs, and GCs). The rest of the paper is organized as follows. The next section presents an up-todate literature review with the main focus on the YT deployment problem at MCTs. The third section describes the main features of the developed simulation model and the simulation objects, while the fourth section describes the numerical experiments, conducted in this study to evaluate the proposed YT deployment strategies. The last section discusses study outcomes and provides conclusions and future research avenues. 


\section{Literature Review}

MCT operations receive a constant attention from the research community. Many studies, conducted in the past, focused on the ITV deployment problem. The main objective of the ITV deployment problem is to allocate available ITVs for the transport of containers between the seaside and the marshaling yard with respect to various operational constraints (i.e., the maximum number of available ITVs, technical characteristics of ITVs, manned vs. automatic equipment, possible congestion issues, collisions, etc.). Four ITV categories were mostly considered by researches in the past: YT, straddle carrier (SC), automated guided vehicle $(\mathrm{AGV})$, and automated lifting vehicle (ALV). YTs and SCs are human operated ITVs, while AGVs and ALVs are automated. YTs and AGVs require additional staking equipment for (un)loading containers. SCs and ALVs are able to handle containers without any additional staking equipment. For a detailed description of ITV technical characteristics this paper refers to ITV manufacturing companies: Kalmar Industries [6], NauticExpo [7], Leibherr [8], Konecranes [9], Terex [10], etc. Since the objective of this study is to evaluate various YT deployment strategies, the literature review presented herein is solely focused on studies related to the YT deployment problem. Review of the collected studies is presented next.

\section{Review of the Relevant Literature}

Bish et al. [11] studied the problem of YT scheduling and routing at MCT. The objective minimized the total YT travel distance. The authors developed a heuristic to solve the problem. The solution procedure was based on two steps: 1) assign locations to jobs; and 2) assign vehicles to the initial part of jobs, and the rest of jobs would be assigned to the first available vehicles. Computational experiments were conducted by varying the numbers of vehicles, serving one QC. It was observed that solutions, obtained by the suggested algorithm, had a small difference with the lower bound. Bish [12] formulated the YT deployment problem, minimizing the total travel time of vehicles. The author introduced assignment and matching problem, when YTs were assigned to deliver import containers to the yard blocks, located close to the ones with export containers. A heuristic was developed to solve the problem. Numerical experiments indicated that the proposed solution approach was efficient for large size problems. Bish et al. [13] studied the YT dispatching problem at MCT. The objective aimed to minimize the vessel service makespan. The authors developed a refined greedy algorithm to solve the problem. Computational experiments showed that the average optimality gap of the proposed solution algorithm comprised $1.55 \%$.

Koo [14] compared several YT dispatching strategies: 1) QC dedicated dispatching; 2) vehicle initiated greedy dispatching; 3) container initiated lookahead dispatching; 4) container initiated idle vehicle dispatching; and 5) the minimum cost flow dispatching. Simulation was used to evaluate those strategies. Numerical examples indicated that the minimum cost flow dispatching policy outperformed the other strategies and yielded the lowest QC idle and vessel turnaround times. Nishmura et al. [15] studied a dynamic YT dispatching policy at MCT, where YTs were able to pick up export containers from the marshalling yard after delivery of containers from the seaside. The objective of the model 
minimized the total YT travel distance. A genetic algorithm was used to solve the problem. The dynamic YT assignment was found to be more efficient than the static one and resulted in $15 \%$ YT fleet size reduction. Zhang et al. [16] proposed three YT scheduling models to determine the sequence of unloading jobs by QCs and the order of vehicles. The first model minimized the total waiting time of jobs, while the second model minimized the last job ready time. The objective of the third model minimized the difference between the last job ready time and the first job ready time. The authors employed a greedy algorithm to solve the problems. Numerical experiments indicated that the third model outperformed the other two models in terms of the QC idle time.

Duinkerken et al. [17] used simulation to analyze three ITV types: YTs, AGVs, and ALVs. The objective minimized the overall idle time of QCs. Computational experiments were performed for Maasvlakte Container Terminals (the Netherlands). Simulation results indicated that almost two times less ALVs were required to obtain the maximum QC productivity as compared to YTs and AGVs. The idle time of AGVs varied from $30 \%$ to $35 \%$, the utilization rate of ALVs comprised around 85\%, while the idle time of YTs was 50\%. Lu and Jeng [18] formulated a non-linear integer programming model for the YT dispatching problem at MCT. A fixed number of YTs were assigned to each QC. The objective aimed to minimize the last job completion time. The authors suggested four YT dispatching principles: closest position, farthest position, closest by farthest, and random selection. The authors developed a heuristic to solve the problem. Computational experiments were performed based on real-life data, collected from the Port of Kaohsiung (Taiwan). It was observed that the closest position YT dispatching yielded the best value of the objective function. Park et al. [19] evaluated two YT dispatching policies: 1) a group of YTs served one particular QC, and 2) a group of YTs was shared between QCs. The objective minimized the average delay in QC operations, caused by YTs. The authors used the Arena simulation software to model those two policies. Numerical experiments were performed using the data from the Hanjin Gamman Container Terminal (South Korea) and demonstrated that the policy, when YTs were shared between QCs, increased the MCT throughput. A productivity of QCs was improved by almost $25 \%$.

Zeng et al. [20] studied a multi-crane oriented scheduling of YTs and developed two models. The first model was based on inter-ship-based sharing of YTs. In the second model YTs could be shared only between QCs, assigned to a particular ship. Objectives of both models aimed to minimize the total operational time. The authors applied a tabu search heuristic to solve the first problem and a Q-learning algorithm to solve the second one. It was observed that inter-ship-based method decreased YT empty travel times, reduced disequilibrium between working lines, and increased the YT utilization. Esmer et al. [21] addressed the YT deployment problem, minimizing the overall environmental damage due to emissions, caused by port operations. The authors used the Arena simulation software to emulate the MCT operations. It was observed that change in the amount of allocated trucks from 5 to 2 would significantly reduce the total environmental damage without affecting the MCT productivity. Lee et al. [22] formulated the YT deployment problem, minimizing the last job completion time. Two heuristics were developed to solve the problem: variable neighborhood search and genetic algorithm. Numerical experiments were performed for small and large 
instance problems. Results demonstrated that the genetic algorithm outperformed the variable neighborhood search in terms of the objective function values.

Nguyen and Kim [23] studied the YT deployment problem at MCT with dynamic environment. The objective minimized the total penalties due to delays in vessel service completion and total YT travel time. The authors used the Plant-Simulation software to solve the problem. Computational experiments indicated that total delays of QCs, total travel time, and empty travel time of vehicles decreased with increasing number of connected nodes in the MCT transportation network. Petering [24] applied a fully-integrated discrete event simulation to evaluate various real-time dual-load YT control systems. Two YT dispatching policies were considered: 1) the most starving QC policy; and 2) the due time policy. It was found that the most starving $\mathrm{QC}$ policy resulted in higher gross QC rate. MCT performance also improved, when all YTs were assigned to one dispatching pool. Dual loading increased the gross QC rate especially for those QCs, which handled one container at the time. Chen et al. [25] formulated the YT deployment problem, minimizing the last task completion time. The authors developed a three-stage heuristic to solve the problem. Computational experiments were conducted using the operational data, collected form the Port of Shanghai (China). It was found that the suggested algorithm obtained solutions, close to the ones, provided by CPLEX, for small size problems, and outperformed the tabu search heuristic for medium and large size instances.

He et al. [26] proposed a mixed integer programming model for the integrated QC, YT, and GC scheduling problem. The objective minimized the total late vessel departures and the total transportation energy consumption. An integrated simulation-based optimization method was developed to solve the problem. Numerical experiments were conducted using the data from the Tianjin Pacific International Container Terminal (China). Results demonstrated that the suggested methodology could be efficient in realization of the optimal trade-off between time and energy savings. Kaveshgar and Huynh [27] studied an integrated QC and YT scheduling problem, minimizing the makespan. The authors developed a heuristic, combining features of the genetic and greedy algorithms. Computational examples indicated that the proposed integrated model produced solutions superior to the ones, obtained from a non-integrated approach. Wang et al. [28] considered an integrated YT and GC scheduling problem, minimizing the weighted summation of the total delay and the total YT travel time. A genetic algorithm with a guided mutation operator was designed to solve the problem. Numerical experiments demonstrated efficiency of the suggested solution algorithm for small and large problem instances.

\section{Contribution}

The review of literature suggests that the YT deployment problem at MCTs is an evolving area of research. However, the published to date studies on the YT deployment problem mostly focused on optimizing only a single performance indicator of a given MCT (e.g., minimize the total YT travel distance or minimize the QC idling time or minimize the makespan, etc.). Nevertheless, in practice MCT operators have to account for multiple performance indicators in order to accurately select the appropriate YT deployment strategy and alleviate potential congestion issues. The contribution of this study to the state of the art and the state of the practice is a novel simulation model that allows assessing 
performance of all equipment types involved in container handling and transfer between the seaside and the marshaling yard of MCT (i.e., QCs, YTs, and GCs) for a given YT deployment strategy and will assist with a more accurate decision making. A total of five candidate YT deployment strategies are presented, and their efficiency is evaluated thorough the extensive simulation experiments based on the key MCT performance indicators.

\section{Model Description}

Modeling MCT operations deals with a number of complex problems (e.g., berth allocation and scheduling, QC allocation and scheduling, GC deployment, etc.) that are difficult to solve using the exact optimization algorithms [29]. Simulation was used in this study to model MCT operations and to evaluate the proposed YT deployment strategies. The simulation model was built using the FlexSim simulation software - FlexSim 7.1.4 [30]. This section presents a detailed description of the developed simulation model, including terminal layout, service of vessels, YT characteristics and deployment strategies, marshaling yard characteristics, marshaling yard handling equipment, and model limitations.

\section{Terminal Layout}

The considered MCT is assumed to have 2 berths. The length of each berth is equal to $400 \mathrm{~m}$, which allows mooring large size vessels (e.g., Neo-Panamax vessels, Emma class vessels, Triple E class vessels, etc.). The width of the apron area, connecting the seaside and the marshaling yard, is set to $90 \mathrm{~m}$. The main MCT geometric characteristics are presented in Figure 3. Note that the MCT layout and dimensions were adopted from the available literature [31][32][33].

\section{Container Flows}

Container flows are illustrated in Figure 4. Service of two vessels will be emulated using the developed simulation model. Three types of containers will be assigned to each vessel: imports, exports, and transshipments (see Figure 4). Imports will be delivered by each vessel, unloaded from the vessel, and transferred to the dedicated storage area of the marshaling yard. Exports will be transferred from the dedicated storage area of the marshaling yard to the assigned vessel. Transshipment containers, delivered by a given vessel, will be unloaded, transferred to the dedicated storage area of the marshaling yard, stored while exports and imports are being handled, and then moved to the assigned vessel at the other berth. MCT performance will be evaluated for different container compositions (i.e., percentages of imports, exports, and transshipments) using the developed simulation model in the numerical experiments section. 


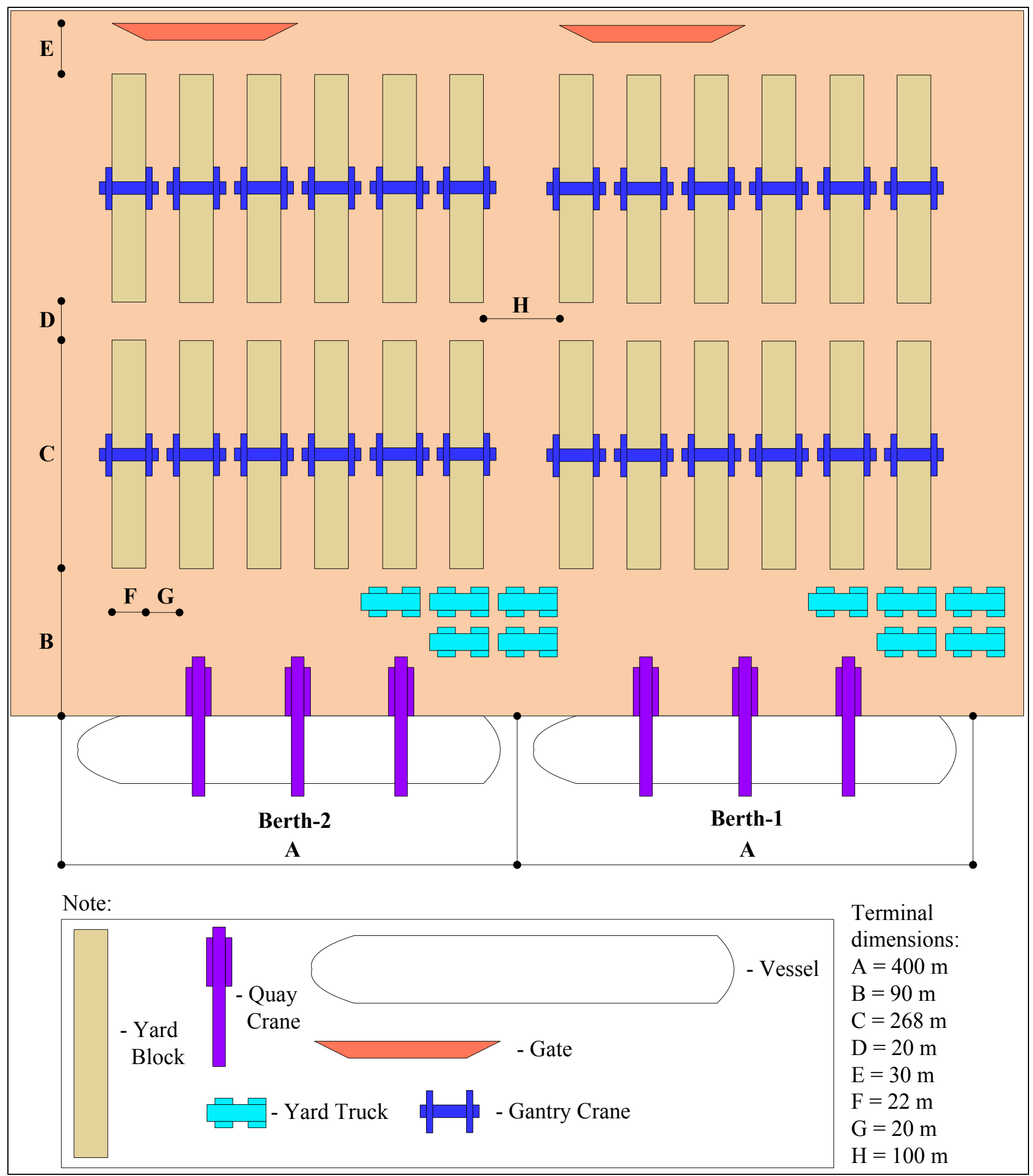

Figure 3: MCT layout. 


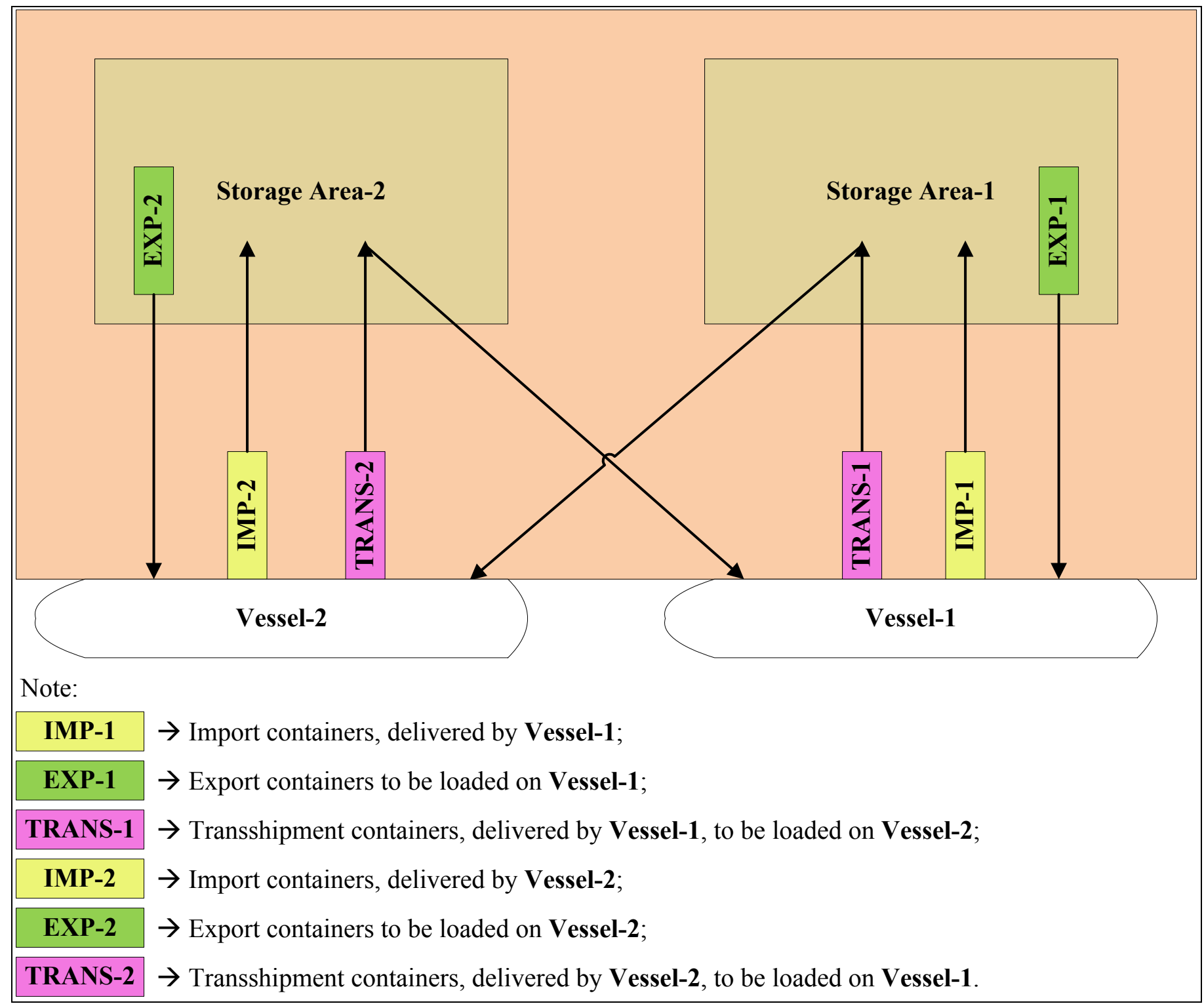

Figure 4: Container flows at MCT.

\section{Service of Vessels}

A gang of QCs is responsible for service of vessels at a given berth. QC productivity (QCP) is assumed to follow a triangular distribution [triangular (1.2, 1.5, 2.0) minutes per container move], which translates to a mean (nominal) value of 40 moves/hour/QC with lower bound of 30 moves/hour/QC and upper bound of 50 moves/hour/QC. Upper bound, lower bound, and mean values of the triangular distribution for QCP were selected based the available literature [31][32][34]. Workload between QCs, serving a given vessel, is equally distributed in the simulation model, as this policy increases productivity by minimizing the vessel handling time [35]. It was further assumed that the stowage plan for each vessel satisfies the stability conditions (e.g., stack weight limit, moment equilibrium between bow and stern and between the left and right side of the vessel). The MCT performance will be evaluated for different sizes of the QC gangs using the developed simulation model in the numerical experiments section. 


\section{YT Characteristics}

It is assumed that the MCT operator deploys YTs to carry containers between the seaside and the marshaling yard (see Figures 1-3). The speed of laden YTs was set to $25 \mathrm{~km} / \mathrm{hr}$., while the speed of empty YTs was set to 40 $\mathrm{km} / \mathrm{hr}$. [31][32]. YTs are assumed to carry one 40 foot (ft.) container (or fortyfoot equivalent unit - FEU), but other container types can be introduced in the simulation model (e.g., $20 \mathrm{ft}$., $45 \mathrm{ft}$., etc.) as well. Vessels are served by two gangs of YTs, each dedicated to serve only a gang of QCs at a particular berth. Several studies confirm that this multi-crane oriented (or pooling) strategy, when YTs are shared between QCs serving the same vessel, is more efficient [19][20]. Productivity of QCs with a multi-crane oriented strategy is approximately $20 \%$ to $25 \%$ higher than the alternative strategy (where YTs are not shared among QCs at the same berth) due to the increase of QC and YT dual cycling.

\section{YT Deployment Strategies}

A total of five YT deployment strategies will be evaluated in this paper using the developed simulation model within the FlexSim environment: 1) First Available - FA; 2) Round Robin - RR; 3) Random Vehicle - RV; 4) Shortest Distance - SD; and 5) Shortest Queue - SQ. Those five strategies are widely used for deployment of vehicles not only in MCTs, but also in the other freight terminals, distribution facilities, and manufacturing plants [30]. The considered YT deployment strategies are presented in Figures 5 and 6 for import and export operations. Note that the transport of transshipments from the seaside will be performed similar to the transport of imports, while the transport of transshipments from the marshaling yard will be performed similar to the transport of exports.

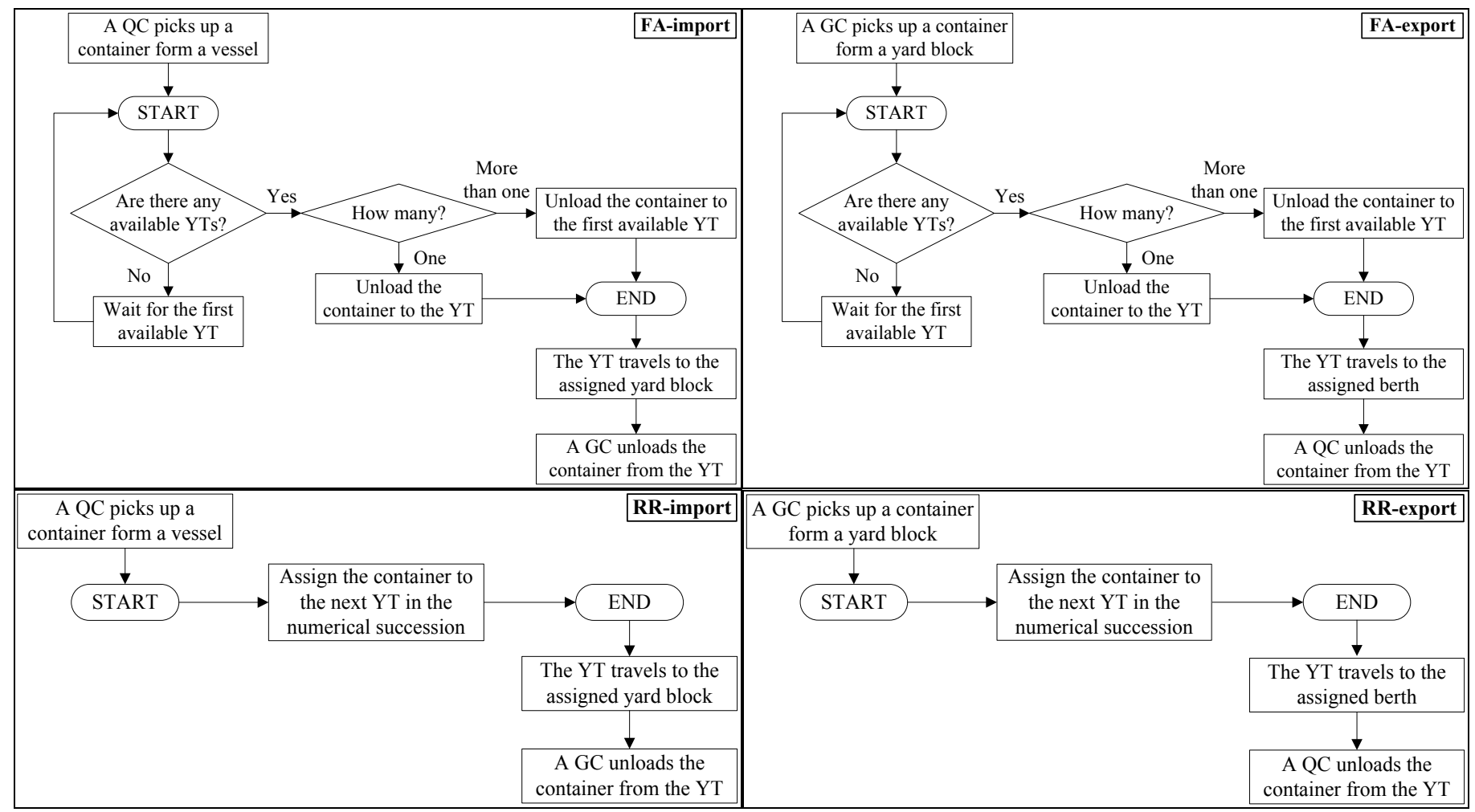

Figure 5: YT deployment strategies: FA and RR. 


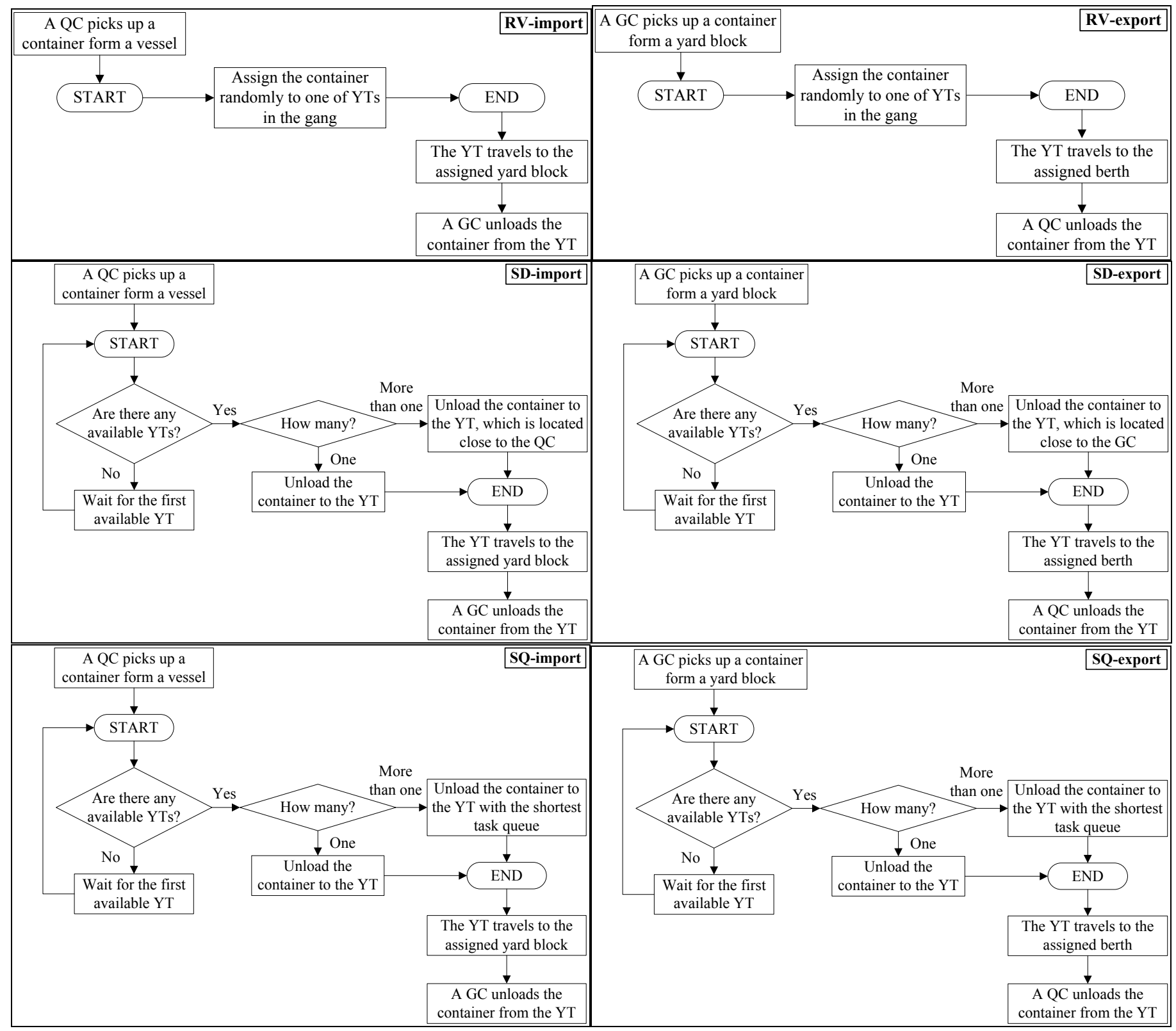

Figure 6: YT deployment strategies: RV, SD, and SQ.

In case of the FA deployment policy, a container, handled by either QC or GC, will be assigned to the first available YT (see Figure 5). As for the RR deployment policy, containers will be assigned to YTs in their numerical succession (see Figure 5). For example, if there are 6 containers to be consecutively unloaded by a given QC, and the YT gang has 3 YTs, containers 1 and 4 will be assigned to the first YT, containers 2 and 5 will be assigned to the second YT, while containers 3 and 6 will be assigned to the third YT. In case of the RV deployment policy, containers will be randomly assigned to YTs in a gang (see Figure 6). As for the SD deployment policy, if there is only one available YT, it will be assigned to pick up the container. If there is more than one YT available to pick up the container, the SD deployment strategy will select the YT, located close to the job at the given simulated time (see Figure 6). The model computes distances between simulation objects based on the terminal's 
road network. If the user did not create the road network, the model will estimate distances based on objects' centroids. As for the SQ deployment strategy, if there is only one available YT, it will be assigned to pick up the container. If there is more than one YT available to pick up the container, the SQ deployment strategy will select the YT, which has the shortest task queue at the given simulated time (see Figure 6). Once the container is loaded on YT, it travels either to the assigned yard block of the marshaling yard (if the container is import or transshipment) or to the QC portal area of the assigned berth (if the container is export or transshipment).

\section{Marshaling Yard Characteristics}

The MCT marshaling yard consists of 24 yard blocks (12 yard blocks per berth, see Figure 3). Each storage area at MCT has separate yard blocks dedicated to import, export, and transshipment containers. The capacity of each block is assumed to be 960 FEUs ( 6 rows $\times 8$ tiers $\times 20$ bays). Length of each bay is set equal to $44 \mathrm{ft}$. (including $4 \mathrm{ft}$. of clearance space). GCs (un)load containers from/to YTs. A specific type of containers (export, import, or transshipment) was assigned to each yard block of the marshaling yard. Import containers are allocated to the blocks, situated closer to the gates. Transshipment containers are placed to the blocks, located closer to the seaside. Export containers are allocated on the side blocks of each storage area. Exports are transported by DTs, passing through the terminal gates. DTs deliver export containers to the assigned yard blocks, once the space is available (queuing occurs when the space is not available). Then GCs unload containers from DTs to the assigned yard blocks. This particular terminal layout was chosen to reduce the total distance traveled by YTs and thus task completion time of YTs, QCs, and GCs.

\section{Marshaling Yard Handling Equipment}

A gang of rubber-tyred GCs is assigned to each storage area of the marshaling yard. Container stacking and retrieval times (i.e., GC productivity GCP) are assumed to follow a triangular distribution [31][32][33] with a nominal value of 20 moves/hour/GC [triangular (2.5, 3.0, 3.3) minutes per container move], including reshuffling time required by a $\mathrm{GC}$ to retrieve a container.

\section{Optimal QCP}

The size of YT and GC gangs, required to obtain the optimal QCP at MCT, was determined based on simulation runs, where the number of YTs was changed from 1 to 40 and the number of GCs from 1 to 30, both with an increment of one. Note that optimal and nominal QCP values differ as the latter is estimated based on the assumption of zero idle time for QCs. The optimal QCP will be less than or equal to the nominal productivity, as it depends on the following factors: a) container demand; b) terminal layout; c) resources (YTs and GCs) allocated to serve QCs (i.e., QCs may have to wait for YTs to become available to pick up/drop-off containers); d) available storage space in the marshalling yard, etc.

\section{Simulation Model Limitations}

The developed simulation model has a number of limitations: 
1) The model does not capture the YT interference. As underlined by Petering et al. [36], this shortcoming had been observed among the existing MCT simulation models, presented in the literature;

2) Congestion issues are not taken into account. For example, if a significant amount of YTs is added in the model (i.e., more than enough to obtain the optimal QCP), the MCT performance won't be affected. Nevertheless, in reality excessive YTs will cause congestion and reduce QCP;

3) Multiple simulation runs are required to estimate the average values of different performance indicators, which is a common requirement for stochastic simulation models;

4) Increasing size of the model (introduction of additional QCs, YTs, and GCs) enlarges its run time;

5) Simplification of MCT operations due to difficulty of their modelling. For example, before making a turn the YT slows down to $3-4 \mathrm{~m} / \mathrm{sec}$. It takes around $10 \mathrm{sec}$ for the YT to make the actual turn (Petering 2010). Furthermore, several factors can affect the YT speed: weather, road condition, time of day (e.g., peak vs. off-peak hour), driver skills, etc. Introduction of the average values or statistical distributions for the YT speed allows capturing all those aspects to a certain extend;

6) Container handling equipment types (i.e., QCs, YTs, and GCs) are assumed to have the same technical characteristics. For example, QCs that serve vessels at a given berth are able to provide the same QCP. The latter may not be the case at certain MCTs (e.g., the MCT operator may utilize QCs with different capacities at the same berth).

Some of those limitations are common for simulation in general as a modeling approach (i.e., limitations 3 and 4). Addressing certain limitations of the simulation model (i.e., limitations 1, 2, and 5) requires development of custom simulation objects (which are not available within FlexSim 7.1.4). The latter objective will be part of the future research avenues.

\section{Numerical Experiments}

The objective of numerical experiments was to evaluate five YT deployment strategies and assess performance of the considered MCT under each one of those strategies. A total of twenty instances were developed in this study to by changing: a) number of QCs at each MCT berth; and b) container composition (i.e., percentage of import, export, and transshipment containers). Values of those input data for each instance are provided in Table 1, including the following information: 1) instance number; 2) number of QCs per berth; and 3) number of imports, exports, and transshipments to be handled for each vessel.

The total demand for each vessel was assumed to be 12000 FEUs with an equal split between import and export containers. The quantity of transshipment containers varies for each instance (see Table 1, column 5). For example, in the first instance (I1) 4500 import and 1500 transshipment containers are unloaded from each vessel, and 4500 export and 1500 transshipment containers are loaded 
on each vessel. In the second instance (I2) 4000 import and 2000 transshipment containers are unloaded from each vessel, and 4000 export and 2000 transshipment containers are loaded on each vessel. Note that the import/export split can be altered in the model (e.g., 70\%-30\% instead of 50\%-50\%), which shall change the amount of GCs serving yard blocks with import and export containers respectively.

Table 1: Simulation model input data.

\begin{tabular}{|c|c|c|c|c|}
\hline Instance & $\#$ QCs & $\begin{array}{c}\text { \# Imports, } \\
\text { FEUs }\end{array}$ & $\begin{array}{c}\text { Exports, } \\
\text { FEUs }\end{array}$ & $\begin{array}{c}\text { Transshipments, } \\
\text { FEUs }\end{array}$ \\
\hline I1 & 3 & 4500 & 4500 & 3000 \\
\hline I2 & 3 & 4000 & 4000 & 4000 \\
\hline I3 & 3 & 3000 & 3000 & 6000 \\
\hline I4 & 3 & 2000 & 2000 & 8000 \\
\hline I5 & 3 & 1500 & 1500 & 9000 \\
\hline I6 & 4 & 4500 & 4500 & 3000 \\
\hline I7 & 4 & 4000 & 4000 & 6000 \\
\hline I8 & 4 & 3000 & 3000 & 8000 \\
\hline I9 & 4 & 2000 & 2000 & 3000 \\
\hline I10 & 4 & 1500 & 1500 & 3000 \\
\hline I11 & 5 & 4500 & 4500 & 4000 \\
\hline I12 & 5 & 4000 & 4000 & 6000 \\
\hline I13 & 5 & 3000 & 3000 & 8000 \\
\hline I14 & 5 & 2000 & 2000 & 9000 \\
\hline I15 & 5 & 1500 & 1500 & 3000 \\
\hline I16 & 6 & 4500 & 4500 & 4000 \\
\hline I17 & 6 & 4000 & 4000 & 6000 \\
\hline I18 & 6 & 3000 & 3000 & 9000 \\
\hline I19 & 6 & 2000 & 2000 & \\
\hline I20 & 6 & 1500 & 1500 & \\
\hline
\end{tabular}

The size of YT gangs and GC gangs, necessary to obtain the optimal QCP, was determined based on simulation runs by varying the number of YTs in a gang from 1 to 40 and the number of GCs in a gang from 1 to 30, both with an increment of one, for each one of the considered instances (i.e., a total of $30 \times 40$ $=1200$ scenarios per instance). Ten replications for each scenario were used to estimate the average values of different MCT performance indicators. The number of replications was found to be sufficient, as the average coefficient of variation for considered performance indicators over all instances and scenarios did not exceed $0.75 \%$ [37]. An additional logic was developed using $\mathrm{C}++$ programming language to export the output file with the state report for the simulation objects in a .csv format at the end of each replication. Next, state report files have been analyzed using a custom program, developed in MATLAB 2014a [38], to compute various MCT performance indicators (presented in the next subsections). Numerical experiments have been performed on a Dell XPS 8700 Intel(T) Core i7 Processor with 8 GB of RAM. Speed of the simulation model averaged on $490 \mathrm{~min} / \mathrm{sec}$. Depending on the models' complexity, the simulation software package used in this study (i.e., FlexSim) allows the 
simulation speed of 200,000 simulation time units per real second. A relatively low simulation speed indicates high complexity of the developed simulation model.

\section{Size of $G C$ and $Y T$ gangs, $Q C P$, and $G C P$}

Examples of the procedure for estimating the size of $\mathrm{YT}$ and GC gangs, required to obtain the optimal QCP, is presented in Figure 7 for instances I16 and I19 (i.e., two out of five instances with the largest amount of QCs at MCT). Each graph provides the following information: a) scenario number and the YT deployment strategy used (title of each graph); b) number of GCs (x-axis); b) number of YTs (y-axis); c) obtained QCP (z-axis); and d) optimal size of YT and GC gangs, which yields the maximum possible QCP (depicted at the top right edge of each graph and labeled by "•"). For example, 11 YTs and 16 GCs were required to obtain the optimal $\mathrm{QCP}=38.0$ moves per hour for instance $\mathrm{I} 16$ at MCT with the FA deployment strategy (see Instance I16 - FA), while 23 YTs and 15 GCs were required to obtain the optimal QCP $=36.4$ moves per hour for the same instance at MCT with the RV deployment strategy (see Instance I16 RV). A similar analysis was performed for each instance. The sizes of YT and GC gangs, required to obtain the optimal QCP for each one of the considered instances, are presented in Table 2, while the obtained QCP and GCP values are provided in Table 3. It was found that on average MCT required 1.7/1.8/2.9/1.7/1.7 YTs per QC and 2.8/2.8/2.9/2.8/2.8 GCs per QC for models with the $\mathrm{FA} / \mathrm{RR} / \mathrm{RV} / \mathrm{SD} / \mathrm{SQ}$ deployment strategies respectively. Thus, the $\mathrm{FA} / \mathrm{SD} / \mathrm{SQ}$ deployment strategies yielded $7.0 \%$ and $66.4 \%$ savings per $\mathrm{QC}$ in terms of YTs as compared to the RR and RV deployment strategies respectively. Furthermore, the FA/RR/SD/SQ deployment strategies provided $2.8 \%$ savings per QC in terms of GCs as compared to the RV deployment strategy. 


\section{Open Science Journal}

Research Article
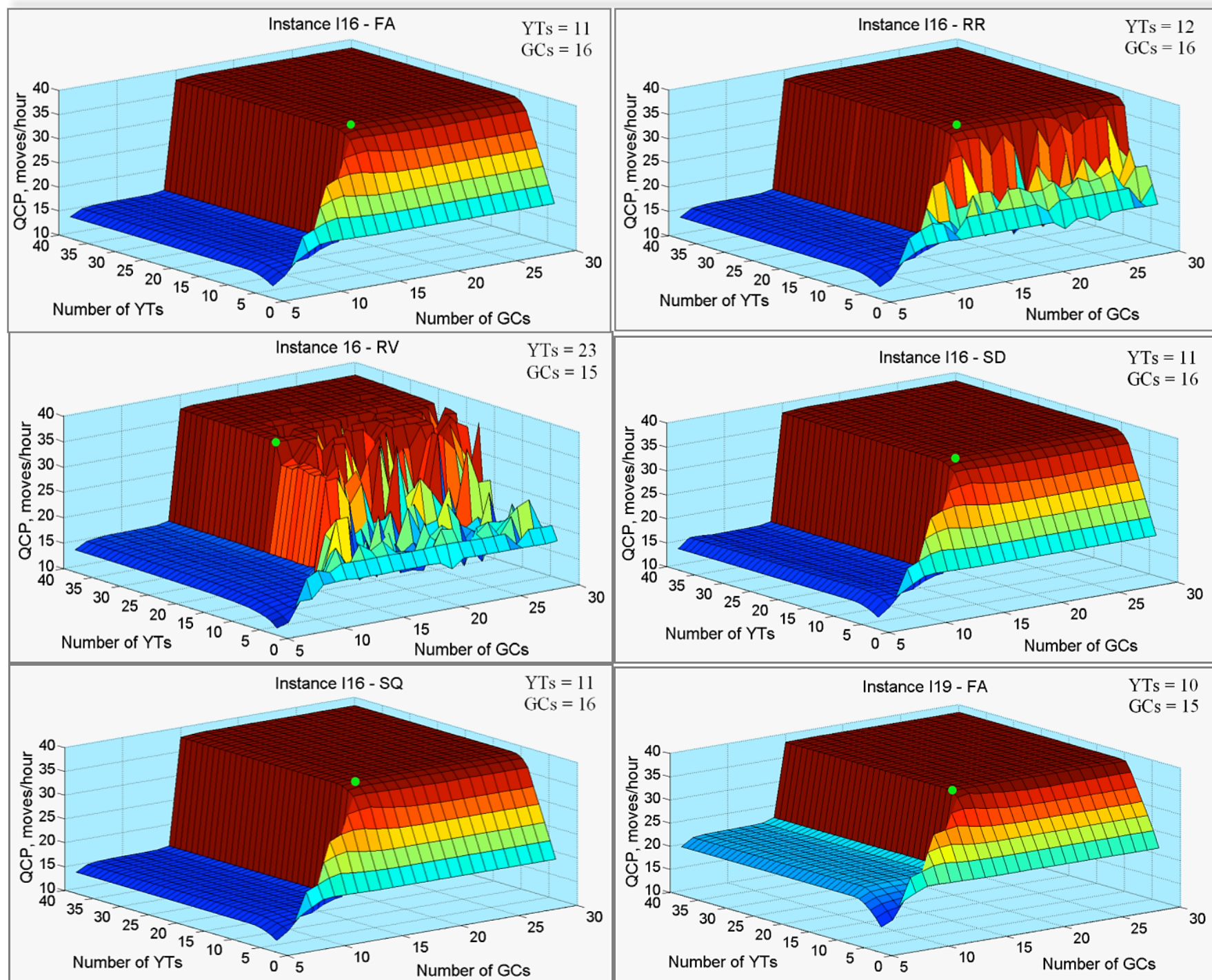

$\begin{array}{ll}\text { Instance I19 - FA } & \text { YTs }=10 \\ & \text { GCs }=15\end{array}$
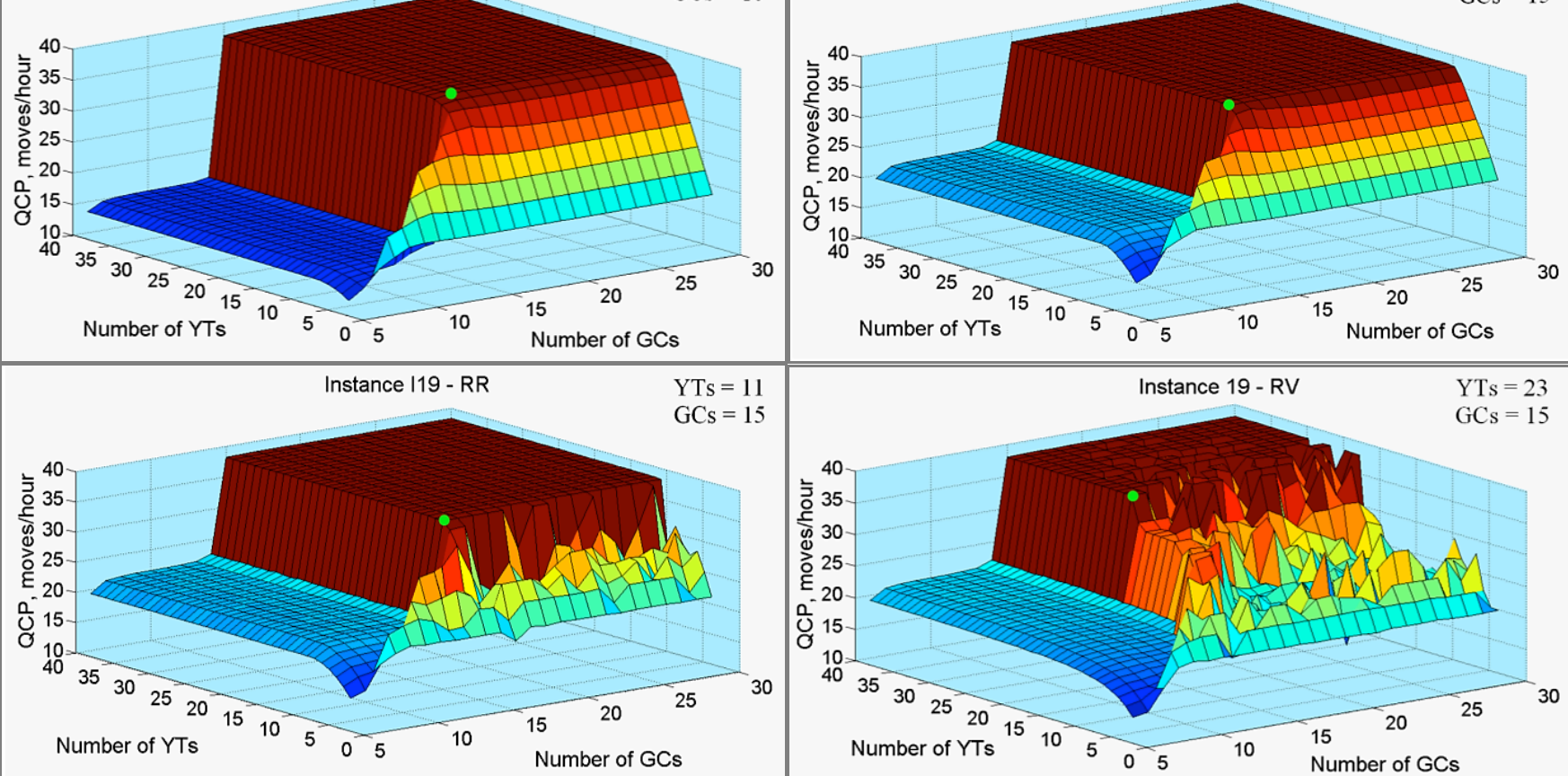

Number of YTs $\quad \begin{array}{llllll}10 & 5 & 0 & 5 & 10 & \end{array}$ Number of GCs

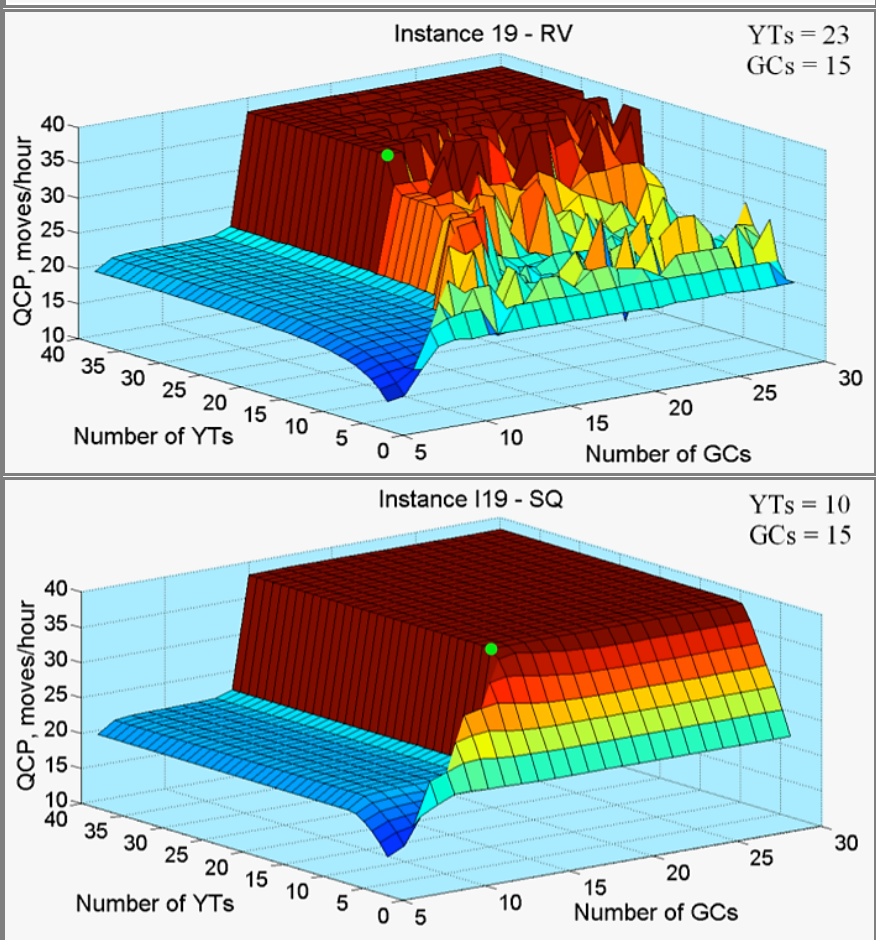

Figure 7: Procedure for estimating size of YT and GC gangs. 
It was observed that increasing percentage of transshipments decreased the size of YT and GC gangs for the majority of instances. For example, MCT with $\mathrm{QCs}=5$ and the FA deployment strategy required 9 YTs and 14 GCs for cases with $25-50 \%$ of transshipments (see Table 2, instances I11-I13), while 8 YTs and 13 GCs were required for cases with $66 \%$ and $75 \%$ of transshipments (see Table 2 , instances I14 and I15). Such decrease in the amount of equipment, necessary to obtain the optimal QCP, can be explained by geometry of the MCT layout. Sum of the travel distance from a given berth to the transshipment yard blocks and the travel distance from the transshipment yard blocks to the other berth (where transshipments will be loaded on the assigned vessel) is smaller as compared to the total distance from a given berth to the import/export yard blocks (due to the fact that the transshipment yard blocks were allocated closer to the seaside, while the import/export yard blocks were allocated closer to the gate), which decreases the total YT travel and GC idle times and in turn yields the equipment savings. Simulation experiments also demonstrated a fluctuation in QCP at MCT with the RV deployment strategy even after reaching the optimal QCP. For example, 23 YTs and 15 GCs were required to obtain the optimal QCP $=36.4$ moves per hour for instance I16 at MCT with the RV deployment strategy (see Figure 7, Instance I16 - RV). However, further increase in a GC gang size from 15 to 19 (with 23 YTs in a gang) leads to decrease in QCP to 21.0 moves per hour (see Figure 7, Instance I16 - RV). The latter observation can be explained by random nature of the RV deployment strategy. As for the FA/RR/SD/SQ deployment strategies, QCP did not fluctuate after its optimal value had been achieved. 
Table 2: Required size of YT and GC gangs.

\begin{tabular}{|c|c|c|c|c|c|c|c|c|c|c|}
\hline \multirow[b]{2}{*}{ Instance } & \multicolumn{2}{|c|}{ FA } & \multicolumn{2}{|c|}{$\mathrm{RR}$} & \multicolumn{2}{|c|}{$\mathrm{RV}$} & \multicolumn{2}{|c|}{$\mathrm{SD}$} & \multicolumn{2}{|c|}{$\mathrm{SQ}$} \\
\hline & $\begin{array}{c}\text { Req. \# } \\
\text { YTs }\end{array}$ & $\begin{array}{c}\text { Req. \# } \\
\text { GCs }\end{array}$ & $\begin{array}{c}\text { Req. \# } \\
\text { YTs }\end{array}$ & $\begin{array}{c}\text { Req. \# } \\
\text { GCs }\end{array}$ & $\begin{array}{c}\text { Req. \# } \\
\text { YTs }\end{array}$ & $\begin{array}{c}\text { Req. \# } \\
\text { GCs }\end{array}$ & $\begin{array}{c}\text { Req. \# } \\
\text { YTs }\end{array}$ & $\begin{array}{c}\text { Req. \# } \\
\text { GCs }\end{array}$ & $\begin{array}{c}\text { Req. \# } \\
\text { YTs }\end{array}$ & $\begin{array}{c}\text { Req. \# } \\
\text { GCs }\end{array}$ \\
\hline I1 & 5 & 9 & 5 & 9 & 6 & 10 & 5 & 9 & 5 & 9 \\
\hline $\mathrm{I} 2$ & 5 & 9 & 5 & 9 & 6 & 10 & 5 & 9 & 5 & 9 \\
\hline I3 & 5 & 9 & 5 & 9 & 6 & 10 & 5 & 9 & 5 & 9 \\
\hline $\mathrm{I} 4$ & 5 & 9 & 5 & 9 & 6 & 10 & 5 & 9 & 5 & 9 \\
\hline $\mathrm{I} 5$ & 5 & 9 & 5 & 9 & 6 & 10 & 5 & 9 & 5 & 9 \\
\hline I6 & 7 & 12 & 8 & 12 & 10 & 12 & 7 & 12 & 7 & 12 \\
\hline $\mathrm{I} 7$ & 7 & 12 & 8 & 12 & 10 & 12 & 7 & 12 & 7 & 12 \\
\hline I8 & 7 & 12 & 8 & 12 & 10 & 12 & 7 & 12 & 7 & 12 \\
\hline I9 & 7 & 11 & 7 & 11 & 9 & 11 & 7 & 11 & 7 & 11 \\
\hline $\mathrm{I} 10$ & 7 & 11 & 7 & 11 & 9 & 11 & 7 & 11 & 7 & 11 \\
\hline $\mathrm{I} 11$ & 9 & 14 & 10 & 14 & 16 & 14 & 9 & 14 & 9 & 14 \\
\hline $\mathrm{I} 12$ & 9 & 14 & 10 & 14 & 16 & 14 & 9 & 14 & 9 & 14 \\
\hline $\mathrm{I} 13$ & 9 & 14 & 10 & 14 & 16 & 14 & 9 & 14 & 9 & 14 \\
\hline $\mathrm{I} 14$ & 8 & 13 & 9 & 13 & 15 & 14 & 8 & 13 & 8 & 13 \\
\hline $\mathrm{I} 15$ & 8 & 13 & 9 & 13 & 15 & 14 & 8 & 13 & 8 & 13 \\
\hline $\mathrm{I} 16$ & 11 & 16 & 12 & 16 & 23 & 15 & 11 & 16 & 11 & 16 \\
\hline $\mathrm{I} 17$ & 11 & 16 & 12 & 16 & 24 & 15 & 11 & 16 & 11 & 16 \\
\hline I18 & 11 & 16 & 11 & 16 & 26 & 15 & 11 & 16 & 11 & 16 \\
\hline I19 & 10 & 15 & 11 & 15 & 23 & 15 & 10 & 15 & 10 & 15 \\
\hline $\mathrm{I} 20$ & 10 & 15 & 11 & 15 & 23 & 15 & 10 & 15 & 10 & 15 \\
\hline $\begin{array}{c}\text { Average } \\
\text { per QC }\end{array}$ & 1.7 & 2.8 & 1.8 & 2.8 & 2.9 & 2.9 & 1.7 & 2.8 & 1.7 & 2.8 \\
\hline
\end{tabular}

Results from the numerical experiments indicate that all the considered YT deployment strategies were able to provide $\mathrm{QCP} \approx 38.0$ moves per hour (see Table 3), which deviates by $5 \%$ form the nominal QCP $=40.0$ moves per hour. As for GCP, all the considered YT deployment strategies were able to provide $\mathrm{GCP} \approx 13.5$ moves per hour, which deviates by $32.5 \%$ form the nominal GCP $=$ 20.0 moves per hour (see Table 3). The latter observation (i.e., inability to achieve GCP close to its nominal value) was noticed by practitioners and from the other MCT simulation models, developed in the past [31][36], and can be explained by the following factors: a) terminal layout - larger YT travel times to the most distant yard blocks (e.g., a GC may be ready for placing the container on the YT, but the YT may be still traveling to that GC after delivering the container to one of $\mathrm{QCs}$ ); b) relocation of GCs between yard blocks, which is considered as an "unproductive" operation (i.e., no containers are placed on YTs or unloaded from YTs); c) QC dependency - imports can be delivered to the assigned yard blocks only after handling by QCs, which causes idling of GCs (similar observation is applicable for export and transshipment operations), etc. 
Table 3: QCP and GCP obtained.

\begin{tabular}{|c|c|c|c|c|c|c|c|c|c|c|}
\hline \multirow[b]{2}{*}{ Instance } & \multicolumn{2}{|c|}{$\mathrm{FA}$} & \multicolumn{2}{|c|}{$\mathrm{RR}$} & \multicolumn{2}{|c|}{$\mathrm{RV}$} & \multicolumn{2}{|c|}{ SD } & \multicolumn{2}{|c|}{$\mathrm{SQ}$} \\
\hline & $\begin{array}{c}\text { QCP, } \\
\text { moves/ } \\
\text { hr. }\end{array}$ & $\begin{array}{c}\text { GCP, } \\
\text { moves/ } \\
\text { hr. }\end{array}$ & $\begin{array}{c}\mathrm{QCP}, \\
\text { moves/ } \\
\text { hr. }\end{array}$ & $\begin{array}{c}\text { GCP, } \\
\text { moves/ } \\
\text { hr. }\end{array}$ & $\begin{array}{c}\mathrm{QCP}, \\
\text { moves/ } \\
\mathrm{hr} .\end{array}$ & $\begin{array}{c}\text { GCP, } \\
\text { moves } \\
/ \text { hr. }\end{array}$ & $\begin{array}{c}\mathrm{QCP}, \\
\text { moves/ } \\
\mathrm{hr} .\end{array}$ & $\begin{array}{c}\text { GCP, } \\
\text { moves/ } \\
\text { hr. }\end{array}$ & $\begin{array}{c}\mathrm{QCP}, \\
\text { moves/ } \\
\text { hr. }\end{array}$ & $\begin{array}{c}\text { GCP } \\
\text { moves/ } \\
\text { hr. }\end{array}$ \\
\hline I1 & 37.3 & 12.4 & 37.3 & 12.4 & 37.5 & 11.3 & 37.2 & 12.4 & 37.3 & 12.4 \\
\hline $\mathrm{I} 2$ & 37.5 & 12.5 & 37.6 & 12.5 & 37.7 & 11.3 & 37.5 & 12.5 & 37.5 & 12.5 \\
\hline I3 & 38.0 & 12.7 & 38.3 & 12.8 & 37.1 & 11.1 & 38.0 & 12.7 & 38.0 & 12.7 \\
\hline I4 & 38.2 & 12.7 & 38.3 & 12.8 & 38.1 & 12.7 & 38.2 & 12.7 & 38.2 & 12.7 \\
\hline $\mathrm{I} 5$ & 38.2 & 12.7 & 38.3 & 12.8 & 37.6 & 11.3 & 38.2 & 12.7 & 38.2 & 12.7 \\
\hline I6 & 37.7 & 12.6 & 38.2 & 12.7 & 37.4 & 12.5 & 37.7 & 12.6 & 37.7 & 12.6 \\
\hline I7 & 37.8 & 12.6 & 38.2 & 12.7 & 37.6 & 12.5 & 37.8 & 12.6 & 37.8 & 12.6 \\
\hline I8 & 38.0 & 12.7 & 38.2 & 12.7 & 37.8 & 12.6 & 38.0 & 12.7 & 38.0 & 12.7 \\
\hline I9 & 38.3 & 13.9 & 38.3 & 13.9 & 38.2 & 13.9 & 38.3 & 13.9 & 38.3 & 13.9 \\
\hline $\mathrm{I} 10$ & 38.3 & 13.9 & 38.3 & 13.9 & 38.2 & 13.9 & 38.3 & 13.9 & 38.3 & 13.9 \\
\hline I11 & 37.9 & 13.5 & 38.1 & 13.6 & 37.1 & 13.3 & 37.9 & 13.5 & 37.9 & 13.5 \\
\hline $\mathrm{I} 12$ & 37.9 & 13.5 & 37.9 & 13.5 & 37.2 & 13.3 & 37.9 & 13.5 & 37.9 & 13.5 \\
\hline $\mathrm{I} 13$ & 38.0 & 13.6 & 38.0 & 13.6 & 37.6 & 13.4 & 38.1 & 13.6 & 38.0 & 13.6 \\
\hline I14 & 37.7 & 14.5 & 38.0 & 14.6 & 38.0 & 13.6 & 37.7 & 14.5 & 37.7 & 14.5 \\
\hline $\mathrm{I} 15$ & 38.0 & 14.6 & 38.3 & 14.7 & 38.3 & 14.7 & 38.0 & 14.6 & 38.0 & 14.6 \\
\hline I16 & 38.0 & 14.2 & 38.0 & 14.2 & 36.4 & 14.6 & 38.0 & 14.2 & 38.0 & 14.2 \\
\hline I17 & 38.0 & 14.3 & 38.0 & 14.3 & 36.7 & 14.7 & 38.0 & 14.3 & 38.0 & 14.3 \\
\hline $\mathrm{I} 18$ & 38.1 & 14.3 & 38.0 & 14.3 & 37.3 & 14.9 & 38.0 & 14.3 & 38.1 & 14.3 \\
\hline I19 & 37.9 & 15.1 & 37.9 & 15.2 & 37.7 & 15.1 & 37.9 & 15.1 & 37.9 & 15.1 \\
\hline $\mathrm{I} 20$ & 38.1 & 15.2 & 38.1 & 15.2 & 38.0 & 15.2 & 38.0 & 15.2 & 38.1 & 15.2 \\
\hline Average & 37.9 & 13.6 & 38.1 & 13.6 & 37.6 & 13.3 & 37.9 & 13.6 & 37.9 & 13.6 \\
\hline
\end{tabular}

\section{Vessel Service Makespan}

The vessel service makespan (i.e., completion time for handling the last container) was retrieved at the end of each replication during the simulation experiments, and obtained values are presented in Figure 8 for all the considered YT deployment strategies, amounts of QCs used, and container compositions. We observe that increasing number of QCs from 3 to 6 decreases the vessel service makespan on average from 105.8 hours $(\approx 4.4$ days $)$ to 52.8 hours $(\approx 2.2$ days $)$. Furthermore, the vessel service makespan values do not change significantly from implementing a different YT deployment strategy. The latter can be explained by the fact that all the considered YT deployment strategies were able to provide almost the same QCP. A minor fluctuation in the vessel service makespan $(\approx 2$ 2.5 hours) can be noticed for the RV deployment strategy. For example, MCT with QCs $=6$ and the RV deployment strategy had a vessel service makespan of 54.9 hours for the case with $25 \%$ of transshipments (see Figure 8, QCs $=6$, Transshipments $=25 \%$ ), while the $\mathrm{FA} / \mathrm{RR} / \mathrm{SD} / \mathrm{SQ}$ deployment strategies on average provided a vessel service makespan of $\approx 52.7$ hours. Such fluctuation is caused by QCP. MCT with QCs $=6$ and the RV deployment strategy had QCP $=36.4$ moves per hour for the case with $25 \%$ of transshipments (see Table 3, 
instance I16), while the $\mathrm{FA} / \mathrm{RR} / \mathrm{SD} / \mathrm{SQ}$ deployment strategies on average provided $\mathrm{QCP} \approx 38.0$ moves per hour.

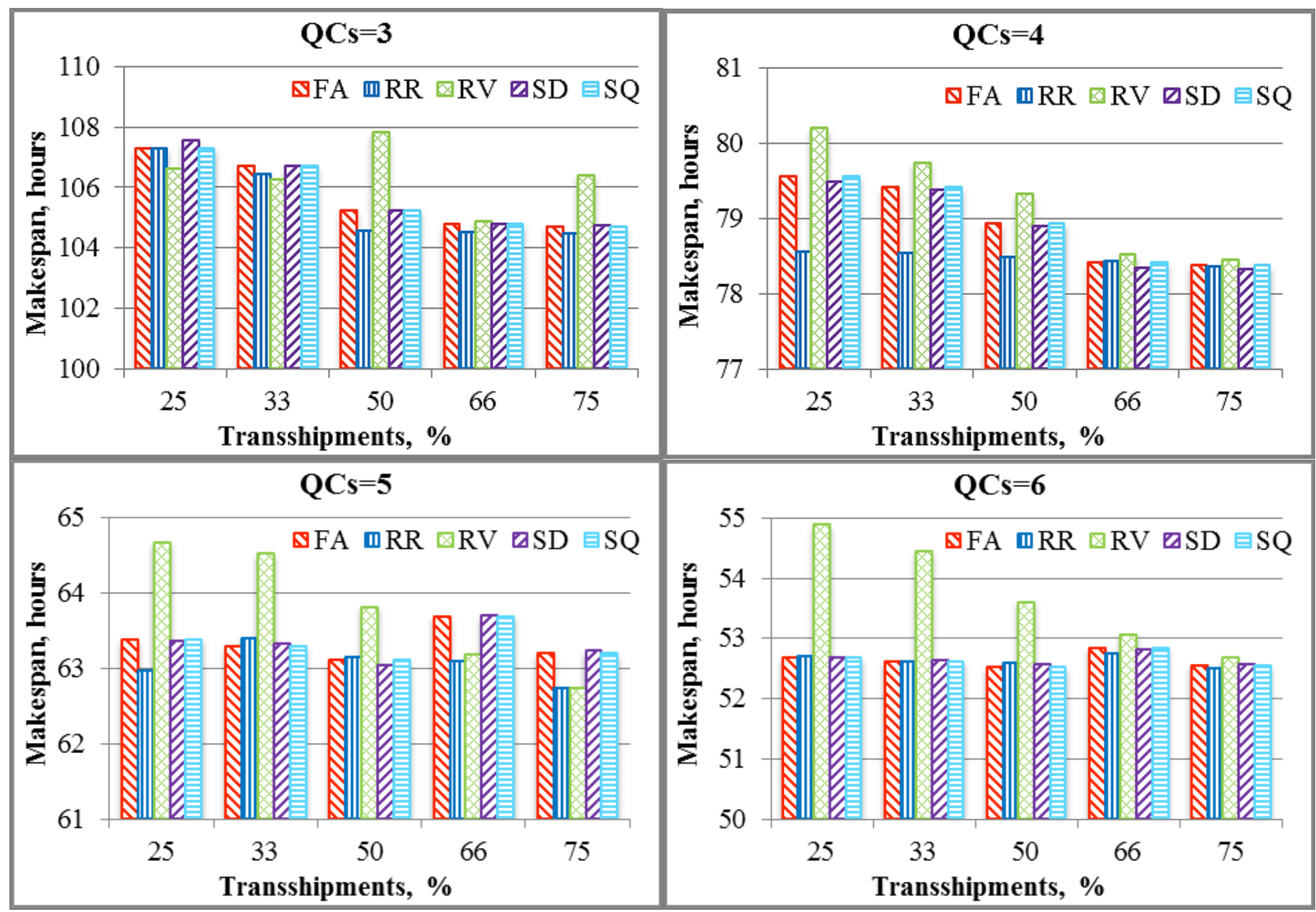

Figure 8: Vessel service makespan.

\section{YT Performance Indicators}

The scope of the numerical experiments included the analysis of YT performance indicators for each one of the considered YT deployment strategies. Results are presented in subsections 4.3.1 and 4.3.2.

\section{$Y T$ states}

States for each YT in a gang were recorded at the end of each replication for each one of the considered instances using the developed simulation model. A total of three states were reported by the model: a) Idle - YT is waiting for a container either at the seaside or the marshalling yard; b) Travel loaded - YT is delivering a container either to the assigned vessel or to the assigned yard block; and c) Travel empty - YT is traveling to pick up a container either from the assigned vessel or from the assigned yard block. The average states (over all YTs in both gangs) are presented in Figure 9 for all the considered YT deployment strategies and instances. Note that YT states are expressed in percentage of the vessel service makespan. It can be observed that the RV deployment strategy yielded the largest idle time (i.e., YTs were under the state "idle"). On average 
YTs could remain idle for up to $74 \%$ of the vessel service makespan, if the RV deployment strategy is used (see Figure 9, State-Idle, Instance I20). The least idle time was recorded for the FA, SD, and $\mathrm{SQ}$ deployment strategies. The least travel empty and travel loaded times were obtained at MCT with the RV deployment strategy (as YTs were idle for a significant amount of time), while the FA, SD, and SQ deployment strategies yielded the largest travel empty and travel loaded times.

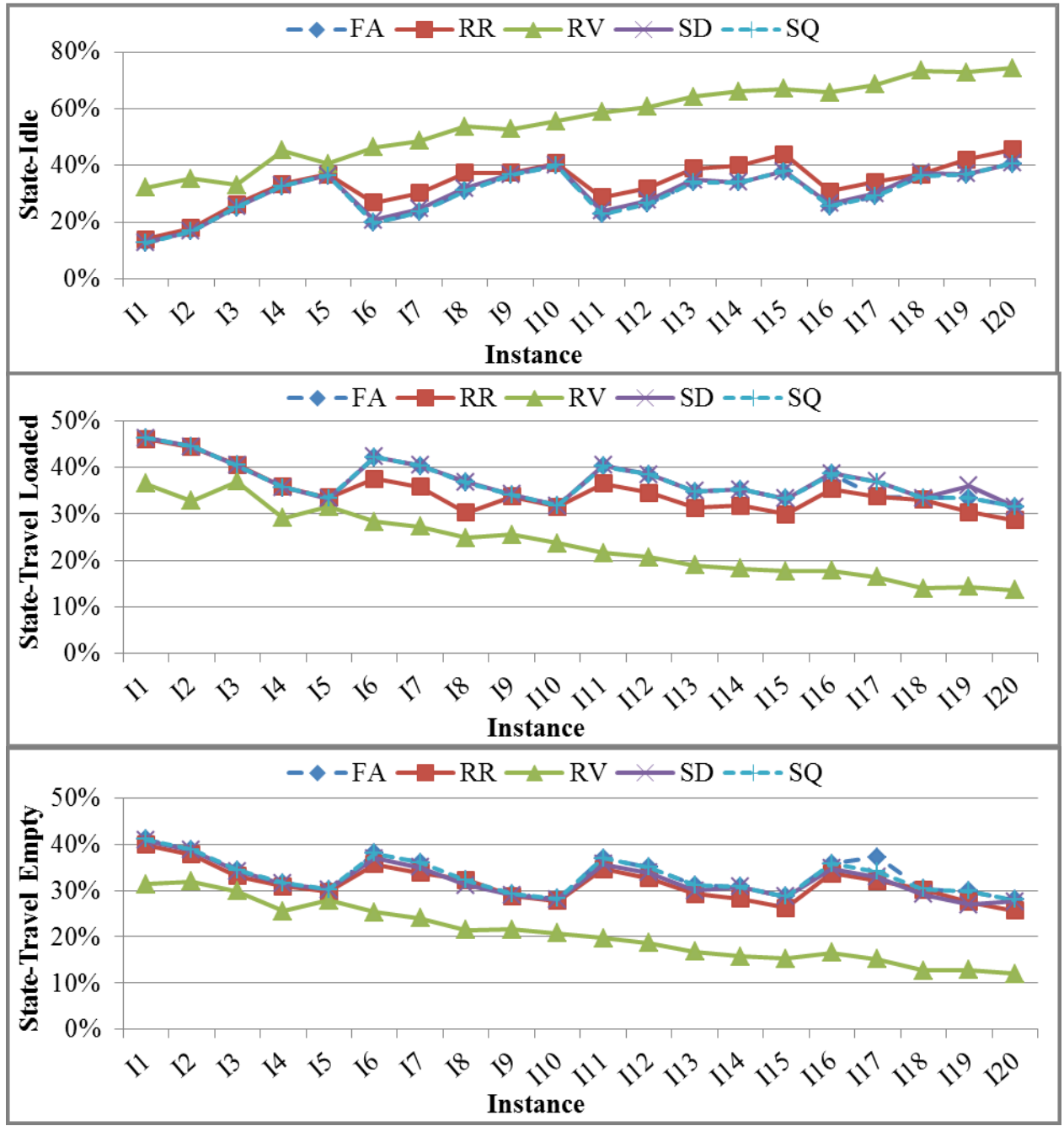

Figure 9: YT states.

Along with the average YT states, standard deviations (STDs) in idle, travel empty, and travel loaded times were computed for each of the YT gangs to determine variability of those performance indicators among YTs in a given gang. Results are presented in Figure 10 for the first YT gang (i.e., the YT gang that serves a vessel at Berth-1, see Figure 3), all the considered YT deployment strategies, and instances. Note that similar results were obtained for the second YT gang due to symmetry of the MCT layout and the same container demand at each berth. The largest STDs can be observed for the FA and SQ deployment strategies, while the least STDs were recorded for the RR and SD deployment strategies. The latter finding indicates that the RR and SD deployment strategies more evenly distribute workload between YTs. 


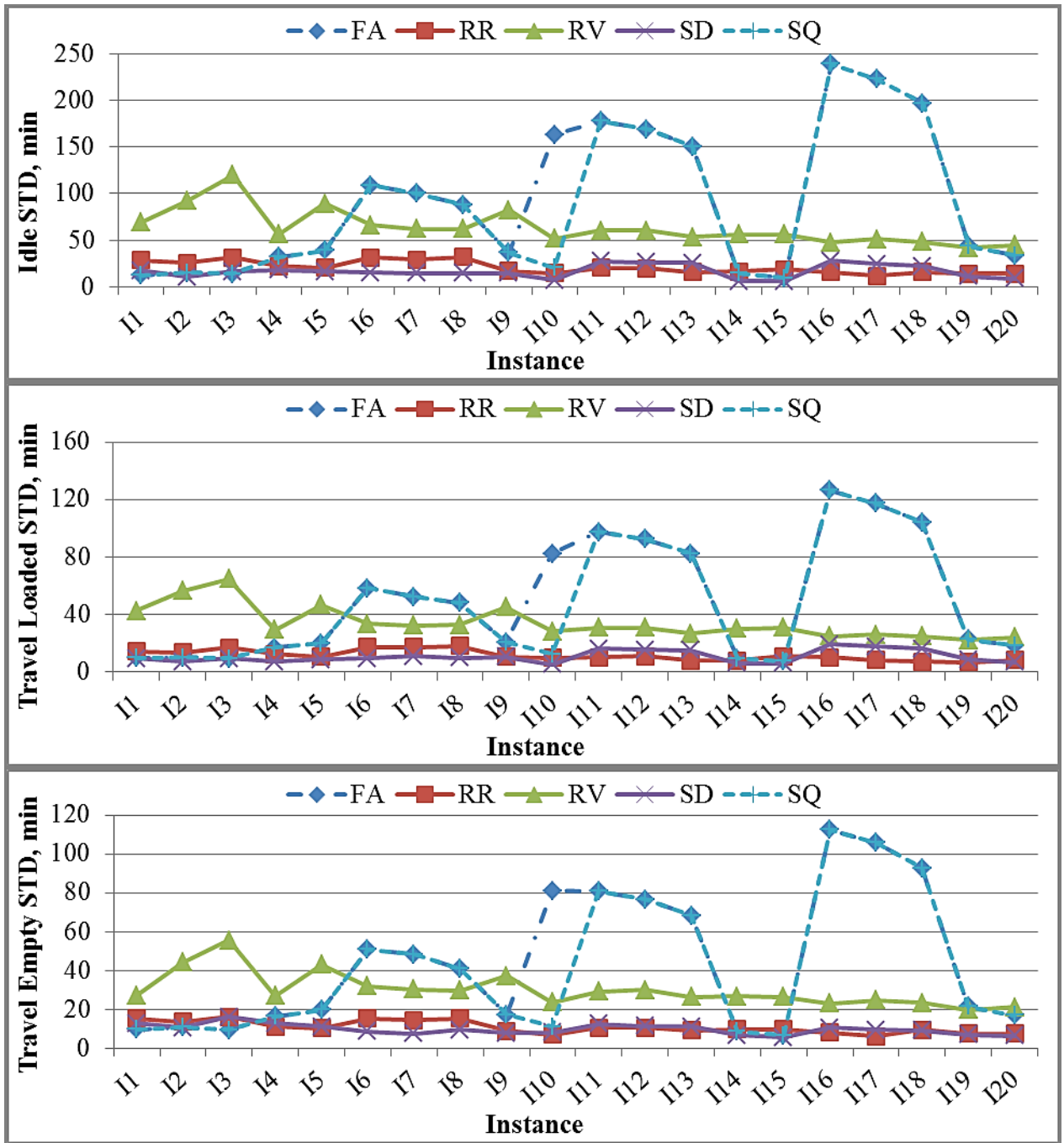

Figure 10: Variability in states between YTs in a gang.

\section{YT travel distance}

As revealed by the conducted literature review, one of the YT deployment problem objectives is to minimize the total YT travel distance [11][12][13][15]. Travel distance is an important performance indicator, which is used as one of the inputs when estimating emissions, produced by YTs [39][40]. The total distance traveled by all YTs at MCT was retrieved at the end of each replication using the developed simulation model, and results are presented in Figure 11 for all the considered YT deployment strategies, amounts of QCs used, and container compositions. We observe that increasing amount of the container handling equipment (i.e., QCs and, hence, YTs and GCs) decreases the total YT travel distance. The latter can be explained by the fact that at MCT with large amount of equipment there are more available jobs at the seaside and the marshaling yard at any given simulated time, which increases probability of YT dual cycling operations (e.g., a YT, delivering an export container from the marshaling yard to the assigned QC, will be assigned to pick an import container from another QC instead of traveling back empty to the marshaling yard). 

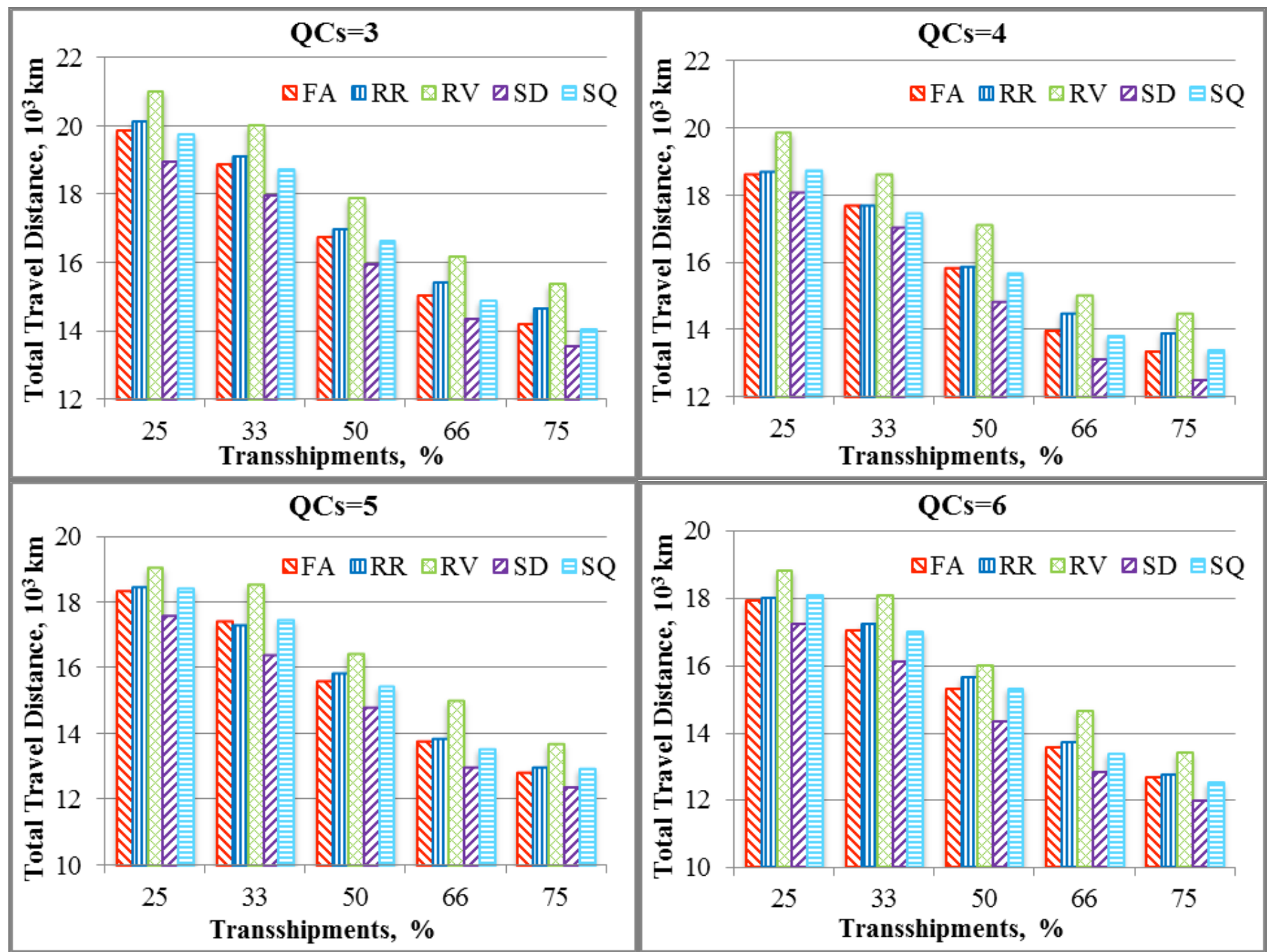

Figure 11: Total YT travel distance.

It can be noticed that increasing amount of transshipment containers decreases the total YT travel distance on average by $\approx 40 \%$. As discussed earlier, the latter observation can be justified by geometry of the MCT layout (i.e., transfer of import/export containers requires YTs to travel longer distances as compared to transfer of transshipment containers). Furthermore, the lowest total YT travel distance was recorded for cases when the SD deployment strategy was used, while the largest total YT travel distance was observed for the RV deployment strategy. The SD deployment strategy outperformed the RV deployment strategy in terms of the total YT travel distance on average by $10.6 \%$, while the $\mathrm{FA} / \mathrm{RR} / \mathrm{SQ}$ deployment strategies were outperformed on average by $5.4 \%$.

\section{Discussion}

All performance indicators, estimated using the developed simulation model for each one of the considered YT deployment strategies, were categorized into 4 groups: 1) Group 1 - vessel service based performance indicators (i.e., vessel 
service makespan); 2) Group 2 - QC based performance indicators (i.e., QCP); 3) Group 3 - GC based performance indicators (i.e., GCP and GC gang size); and 4) Group 4 - YT based performance indicators (i.e., YT gang size, YT idle time, YT travel loaded time, YT travel empty time, YT idle time STD, YT travel loaded time STD, YT travel empty time STD, and the total YT travel distance). Next all five YT deployment strategies were given a rank (from 1 - "best" to 5 "worst") based on the average values of performance indicators over all considered instances. Equal ranks were given if values of performance indicators were the same or within a $5 \%$ range. Ranking of the YT deployment strategies for each performance indicator is presented in Table 4, while the average and total rank values by performance indicators' group are provided in Table 5 .

Note that depending on the MCT operator's preferences/objectives additional weights can be assigned to each performance indicator to calculate the weighted average ranks. We observe that all five YT deployment strategies have the same rank for the vessel service and QC performance indicators (group 1 and group 2). As for the GC performance indicators, the RV deployment strategy is outperformed by the $\mathrm{FA} / \mathrm{RR} / \mathrm{SD} / \mathrm{SQ}$ deployment strategies. As for the $\mathrm{YT}$ performance indicators, the SD deployment strategy has the best rank, followed by the RR and SQ deployment strategies. The worst rank is given to the RV deployment strategy.

Table 4: Ranking of the YT deployment strategies.

\begin{tabular}{|c|l|c|c|c|c|c|c|}
\hline \multirow{2}{*}{ № } & \multirow{2}{*}{ Performance indicator } & \multirow{2}{*}{ Group } & \multicolumn{3}{|c|}{ YT deployment strategy/Rank } \\
\cline { 4 - 8 } & & & FA & RR & RV & SD & SQ \\
\hline 1 & Vessel service makespan & 1 & 1 & 1 & 1 & 1 & 1 \\
\hline 2 & QCP & 2 & 1 & 1 & 1 & 1 & 1 \\
\hline 3 & GCP & 3 & 1 & 1 & 1 & 1 & 1 \\
\hline 4 & GC gang size & 3 & 1 & 1 & 2 & 1 & 1 \\
\hline 5 & YT gang size & 4 & 1 & 2 & 3 & 1 & 1 \\
\hline 6 & YT idle time & 4 & 1 & 2 & 3 & 1 & 1 \\
\hline 7 & YT travel loaded time & 4 & 1 & 2 & 3 & 1 & 1 \\
\hline 8 & YT travel empty time & 4 & 1 & 2 & 3 & 1 & 1 \\
\hline 9 & YT idle time STD & 4 & 5 & 2 & 3 & 1 & 4 \\
\hline 10 & YT travel loaded time STD & 4 & 5 & 2 & 3 & 1 & 4 \\
\hline 11 & YT travel empty time STD & 4 & 5 & 2 & 3 & 1 & 4 \\
\hline 12 & Total YT travel distance & 4 & 3 & 4 & 5 & 1 & 2 \\
\hline
\end{tabular}

Table 5: Average and total rank values.

\begin{tabular}{|c|c|c|c|c|c|c|c|c|c|c|}
\hline \multirow{2}{*}{ Group } & \multicolumn{4}{|c|}{ YT deployment strategy/Average rank } & \multicolumn{4}{c|}{ YT deployment strategy/Total rank } \\
\cline { 2 - 13 } & FA & RR & RV & SD & SQ & FA & RR & RV & SD & SQ \\
\hline 1 & 1.00 & 1.00 & 1.00 & 1.00 & 1.00 & 1 & 1 & 1 & 1 & 1 \\
\hline 2 & 1.00 & 1.00 & 1.00 & 1.00 & 1.00 & 1 & 1 & 1 & 1 & 1 \\
\hline 3 & 1.00 & 1.00 & 1.50 & 1.00 & 1.00 & 2 & 2 & 3 & 2 & 2 \\
\hline 4 & 2.75 & 2.25 & 3.25 & 1.00 & 2.25 & 22 & 18 & 26 & 8 & 18 \\
\hline \multicolumn{9}{|c}{} & \multicolumn{9}{|c}{ Overall: } & 26 & 22 & 31 & 12 & 22 \\
\hline
\end{tabular}


Thus, the analysis of results from the simulation experiments indicates that the SD deployment strategy can provide more efficient MCT operations as compared to the $\mathrm{FA} / \mathrm{RR} / \mathrm{RV} / \mathrm{SQ}$ deployment strategies. Furthermore, random assignment of jobs to YTs (i.e., the RV deployment strategy) may worsen the MCT performance, require more GCs and YTs for container handling and transfer, result in longer travel distances by YTs, increase YT idle time, etc. Due to the complexity of MCT operations changes in the input data (i.e., terminal layout, technical characteristics of container handling and transfer equipment, demand, container composition) may affect the values of performance indicators for a given YT deployment strategy. However, the developed simulation model will be able to capture those changes in the input data and recalculate the performance indicators, which may further assist MCT operators to select the best YT deployment strategy, determine the required size of GC and YT gangs, evenly distribute workload between YTs, decrease idle time of handling equipment, and reduce the turnaround time of vessels.

\section{Conclusions and Future Research}

Increasing volumes of the international seaborne trade and increasing port congestion require marine container terminal operators to improve efficiency of the terminal operations, avoid potential delays in service of vessels, and ensure timely delivery of goods to customers. This study focused on evaluation of different yard truck deployment strategies to improve container transfer between the seaside and the marshalling yard of a marine container terminal. Marine container terminal operations were modeled via simulation. A total of five yard truck deployment strategies were compared based on various performance indicators. Different performance indicators were estimated to determine how the proposed yard truck deployment strategies would affect all equipment types, involved in container transfer and handling. Results of a comprehensive simulation analysis indicate that all five yard truck deployment strategies demonstrated similar vessel service and quay crane performance indicators, while the shortest distance based yard truck deployment strategy had superior gantry crane and yard truck performance indicators. The worst values of performance indicators were recorded for the random yard truck deployment strategy. The developed simulation model was found to be an efficient tool for terminal planning and could be used by marine container terminal operators to select of the best yard truck deployment strategy, determine the amount of necessary equipment for container transfer and handling, evenly distribute workload between yard trucks, decrease idle time of handling equipment, and reduce the turnaround time of vessels.

The scope of future research may focus on the following: a) develop custom simulation objects to address limitations of the developed simulation model; b) introduce storage areas in the marshaling yard for hazmat, overweight, oversized, and refrigerated containers; c) evaluate the proposed yard truck deployment strategies for marine container terminals with different layouts and container demands; d) develop hybrid yard truck deployment strategies (i.e., yard truck deployment strategies that combine features of the strategies, evaluated in this 
study); and e) assess terminal resilience for the proposed yard truck deployment strategies.

\section{References}

[1] Journal of Commerce, 2014. Congestion hurts carriers' schedule reliability, SeaIntel says. http://www.joc.com. Accessed 2 February 2016

[2] Journal of Commerce, 2015. LA throughput grows in May, clouding impact of diversions. http://www.joc.com. Accessed 2 February 2016

[3] American Shipper, 2015. Best practices and collaboration for curbing port congestion. White paper

[4] World Shipping Council, 2015. Some observations on port congestion, vessel size and vessel sharing agreements. http://www.worldshipping.org. Accessed 21 January 2016

[5] Dulebenets, M.A., Pujats, K., Golias, M.M., Mishra, S., 2016. Megaships in marine transportation: A critical literature review and extensions. In Transportation Research Board 95th Annual Meeting (No. 16-4014)

[6] Kalmar Industries, 2016. Kalmar solutions set the benchmark for energy efficiency, reliability and lifetime value. https://www.kalmarglobal.com/equipment. Accessed 21 January 2016

[7] NauticExpo, 2016. Boat handling. http://www.nauticexpo.com/cat/boat-handling-AC.html. Accessed 21 January 2016

[8] Leibherr, 2016. Product information. http://www.liebherr.us/en-GB/80390.wfw. Accessed 21 January 2016

[9] Konecranes, 2016. Equipment. http://www.konecranes.com/equipment. Accessed 21 January 2016

[10] Terex, 2016. Products overview. http://www.terex.com/port-solutions/en/index.htm\# products. Accessed 21 January 2016

[11] Bish, E., Leong, T., Li, C., Ng, J., Simchi-Levi, D., 2001. Analysis of a New Vehicle Scheduling and Location Problem. Naval Research Logistics 48:363-385

[12] Bish, E., 2003. A multiple-crane-constrained scheduling problem in a container terminal. European Journal of Operational Research 144:83-107

[13] Bish, E., Chen, F., Leong, Y., Nelson, B., Ng, J., Levi, D., 2005. Dispatching vehicles in a mega container terminal. OR Spectrum 27:491-506

[14] Koo, P., 2013. Dispatching transport vehicles at marine container terminals. International Journal of Business Tourism and Applied Sciences 1:90-97

[15] Nishmura, E., Imai, A., Paradimitriou, S., 2005. Yard trailer routing at a maritime container terminal. Transportation Research Part E 41:53-76

[16] Zhang, L., Ye, R., Huang, S., Hsu, W., 2005. Mixed integer programming models for dispatching vehicles at a container terminal. Journal of Applied Mathematics and Computing 17:145 - 170

[17] Duinkerken, M., Dekker, R., Kurstjens, S., Ottjes, J., Dellaert, N., 2006. Comparing transportation systems for inter-terminal transport at the Maasvlakte container terminals. Container Terminals and Cargo Systems, Springer, pp. 37-61

[18] Lu, H., Jeng, J., 2006. Modeling and solution for yard truck dispatch planning at container terminal. Operations Research Proceedings 2005, Springer, pp. 117-122

[19] Park, N., Dragovic, B., Kim, J., 2009. Dynamic equipment deployment at a container terminal: transfer system based on real-time positioning. Journal of Mechanical Engineering 55:83-94

[20] Zeng, Q., Yang, Z., Lai, L., 2009. Models and algorithms for multi-crane oriented scheduling method in container terminals. Transport Policy 16:271-278

[21] Esmer, S., Cetin, I., Tuna, O., 2010. A Simulation for Optimum Terminal Truck Number in a Turkish Port Based on Lean and Green Concept. The Asian Journal of Shipping and Logistics 26:277-296

[22] Lee, L., Chew, E., Tan, K., Wang, Y., 2010. Vehicle dispatching algorithms for container transshipment hubs. OR Spectrum 32:663-685

[23] Nguyen, V., Kim, K., 2010. Dispatching vehicles considering uncertain handling time at port container terminals. Department of Industrial Engineering, Pusan National University, Busan, Korea

[24] Petering, M., 2010. Development and simulation analysis of real-time, dual-load yard truck control systems for seaport container transshipment terminals. OR Spectrum 32:663-661

[25] Chen, L., Langevin, A., Lu, Z., 2013. Integrated scheduling of crane handling and truck transportation in a marine container terminal. European Journal of Operational Research $225: 142-152$ 
[26] He, J., Huang, Y., Yan, W., Wang, S., 2015. Integrated internal truck, yard crane and quay crane scheduling in a container terminal considering energy consumption. Expert Systems with Applications 42:2464-2487

[27] Kaveshgar, N., Huynh, N., 2015. Integrated quay crane and yard truck scheduling for unloading inbound containers. International Journal of Production Economics 159:168-177

[28] Wang, Z., Chan, F., Chung, S., Niu, B., 2015). Minimization of delay and travel time of yard trucks in container terminals using an improved GA with guidance search. Mathematical Problems in Engineering 2015:1-12

[29] Carlo, H., Vis, I., Roddbergen, K., 2013. Seaside operations in container terminals: literature overview, trends, and research directions. Journal of Production Research 49:6199-6226

[30] FlexSim, 2016. FlexSim simulation software. http://www.flexsim.com/flexsim. Accessed 27 January 2016

[31] Petering, M., Murty, K., 2008. Effect of block length and yard crane deployment systems on overall performance at a seaport container transshipment terminal. Computers \& Operations Research 156:1-15

[32] Dulebenets, M.A., 2015. Models and solution algorithms for improving operations in marine transportation. Dissertation, University of Memphis

[33] Dulebenets, M.A., Golias, M., Mishra, S., Heaslet, W., 2015. Evaluation of the floaterm concept at marine container terminals via simulation. Simulation Modelling Practice and Theory 54:1935

[34] Dulebenets, M.A., Golias, M., Mishra, S., 2015. The green vessel schedule design problem: consideration of emissions constraints. Energy Systems, pp. 1-23

[35] Song, L., Cherrett, T., Guan, W., 2012. Study on berth planning problem in a container seaport: using an integrated programming approach. Computers \& Industrial Engineering 62:119-128

[36] Petering, M., 2009. Effect of block width and storage yard layout on marine container terminal performance. Transportation Research Part E 4:591-610

[37] Pritsker, A., Pegden, C., 1979. Introduction to simulation and SLAM. John Wiley \& Sons, Inc., New York

[38] MathWorks, 2016. MATLAB - Release 2014a. http://www.mathworks.com/support/sysreq/ svr2014a/. Accessed 21 January 2016

[39] Browning, L., Bailey, K., 2006. Current methodologies and best practices for preparing port emission inventories. ICF Consulting report to Environmental Protection Agency

[40] Lindjhem, C., 2008. Intermodal yard activity and emissions evaluations. In Proceedings of the US EPA 17th International Emission Inventory Conference, pp. 2-5 